\title{
Three Essays on Renewable Energy Policy and its Effects on Fossil Fuel Generation in Electricity Markets
}

Eric Bowen

Follow this and additional works at: https://researchrepository.wvu.edu/etd

\section{Recommended Citation}

Bowen, Eric, "Three Essays on Renewable Energy Policy and its Effects on Fossil Fuel Generation in Electricity Markets" (2015). Graduate Theses, Dissertations, and Problem Reports. 5242.

https://researchrepository.wvu.edu/etd/5242

This Dissertation is protected by copyright and/or related rights. It has been brought to you by the The Research Repository @ WVU with permission from the rights-holder(s). You are free to use this Dissertation in any way that is permitted by the copyright and related rights legislation that applies to your use. For other uses you must obtain permission from the rights-holder(s) directly, unless additional rights are indicated by a Creative Commons license in the record and/ or on the work itself. This Dissertation has been accepted for inclusion in WVU Graduate Theses, Dissertations, and Problem Reports collection by an authorized administrator of The Research Repository @ WVU.

For more information, please contact researchrepository@mail.wvu.edu. 


\title{
Three Essays on Renewable Energy Policy and its Effects on Fossil Fuel Generation in Electricity Markets
}

\author{
Eric Bowen \\ Dissertation submitted to the College of Business and Economics \\ at West Virginia University in partial fulfillment of the \\ requirements for the degree of Doctor of Philosophy in the \\ Department of Economics \\ Committee: \\ Stratford Douglas, $\mathrm{PhD}$, Chair \\ Wesley Burnett, PhD \\ Brian Cushing, $\mathrm{PhD}$ \\ John Deskins, PhD \\ Donald Lacombe, $\mathrm{PhD}$ \\ Department of Economics \\ Morgantown, West Virginia \\ 2015
}

Keywords: Renewable Energy, Renewable Portfolio Standards, Renewable Energy Policy, Spatial Econometrics, Electricity Markets, Coal, Natural Gas, Power Generation

(C) Copyright 2015 Eric Norman Bowen 


\title{
Abstract \\ Three Essays on Renewable Energy Policy and its Effects on Fossil Fuel Generation in Electricity Markets
}

\author{
Eric Bowen
}

In this dissertation, I investigate the effectiveness of renewable policies and consider their impact on electricity markets. The common thread of this research is to understand how renewable policy incentivizes renewable generation and how the increasing share of generation from renewables affects generation from fossil fuels. This type of research is crucial for understanding whether policies to promote renewables are meeting their stated goals and what the unintended effects might be. To this end, I use econometric methods to examine how electricity markets are responding to an influx of renewable energy. My dissertation is composed of three interrelated essays. In Chapter 1, I employ recent scholarship in spatial econometrics to assess the spatial dependence of Renewable Portfolio Standards (RPS), a prominent state-based renewable incentive. In Chapter 2, I explore the impact of the rapid rise in renewable generation on shortrun generation from fossil fuels. And in Chapter 3, I assess the impact of renewable penetration on coal plant retirement decisions. 


\section{Acknowledgements}

I would first like to thank my committee, which has been a source of inspiration during the process of writing this dissertation. Stratford Douglas has spent numerous hours shaping this project from the beginnings of an idea to fruition. Donald Lacombe has provided many suggestions for improvement. Wesley Burnett has been a source of wisdom throughout. John Deskins has been a great colleague, in addition to being a helpful committee member. Lastly, Brian Cushing has believed all along that I could make it.

Several other people were instrumental in helping me along this road. Mark Witte helped spark a lifelong interest in economics. George Hammond helped me decide to go back to school to study economics. Randall Jackson gave me my first paying job as an economist, and Tom Witt gave me my second. Nancy McIntyre kept asking me if I was done yet. Zheng Tian and Christa Jensen Court were fantastic RRI office-mates and friends. Kirill Temlyakov played a mean game of chess. The Adams - Pellillo and Hoffer - helped get me through my coursework. And to Annie Walker, who understood the difficulties of going back to school as a non-whippersnapper: I treasure our friendship.

I also want to thank my many parents, Barbara and Steve Benjamin, Steve Bowen and Isa Fernandez, and Margo Brinton. In particular, mom, thank you for coming to my aid in the dark days toward the end when I was not sure I would ever get finished. I also thank Jan and Len Carpenter, who have put up with their moody son-in-law through many years of work. And I thank my sister, Kristine Bowen, who has been supportive during this time of transition. Thank you all for being great parents, grandparents, and siblings.

Finally, this dissertation is dedicated above all to my wife, Cari Carpenter, and my daughter, Adalyn Carpenter-Bowen. Cari, I know you know how much I have relied on you to keep me going and sane through the times I thought about quitting. I hope you also know how much it has meant to me, and how much I love you. You gave me the best advice I received in this entire process, "The best dissertation is a finished dissertation." And to Adalyn: I'm sorry for all of those times when papa was stuck doing my "calculations" instead of going to the park or watching your gymnastics lessons. I promise to do better. 


\section{Table of Contents}

List of Figures and Tables ................................................................................... v

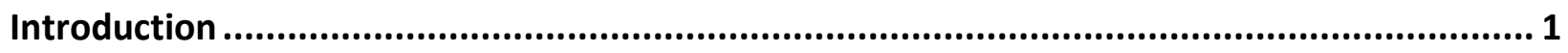

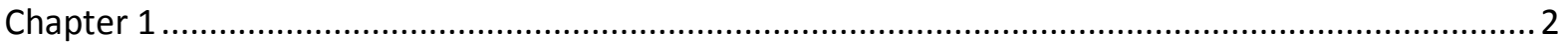

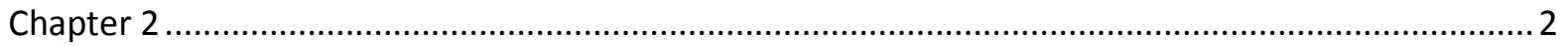

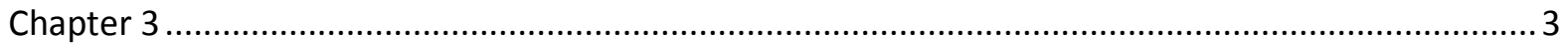

Chapter 1 : Spatial dependence of Renewable Portfolio Standards and their effect on renewable generation within NERC regions .............................................................5 5

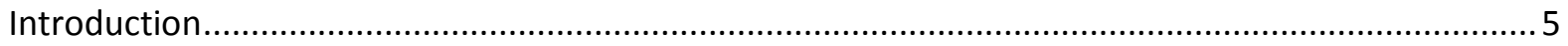

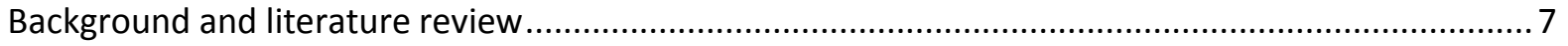

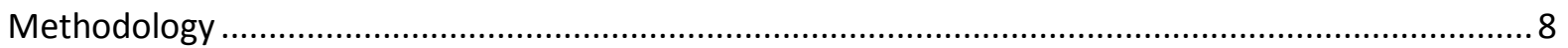

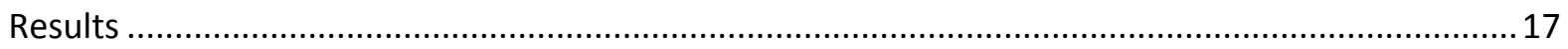

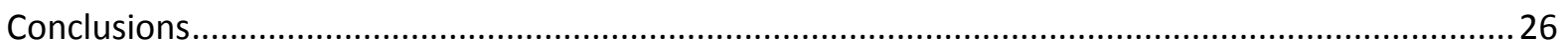

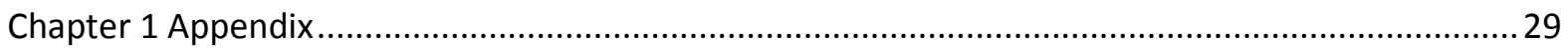

Chapter 2 : Short-run effects of regional renewable penetration on the fossil fuel mix in

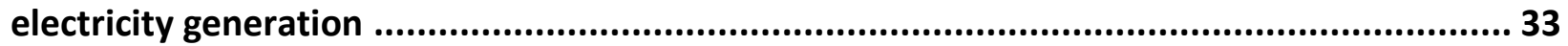

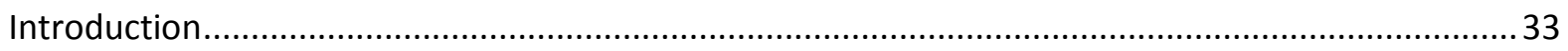

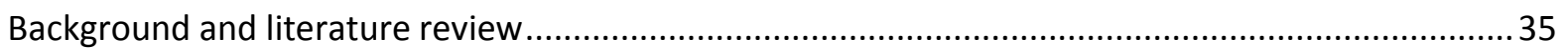

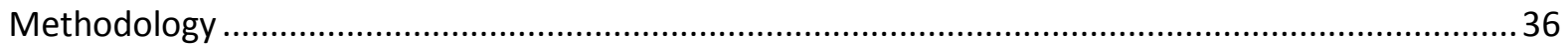

Data

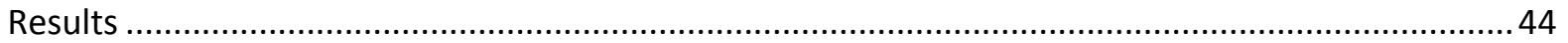

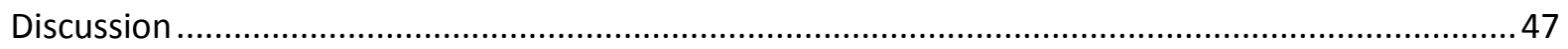

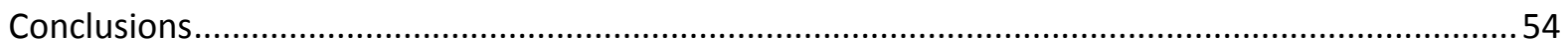

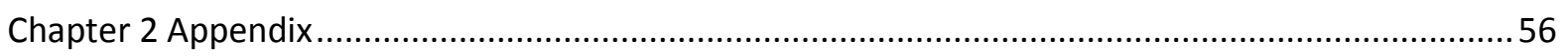

Chapter 3 : Drivers of coal-fired capacity retirements in electricity markets ...................... 57

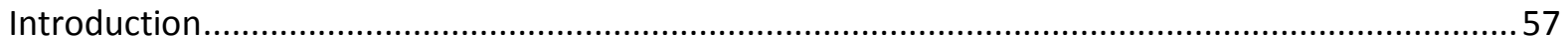

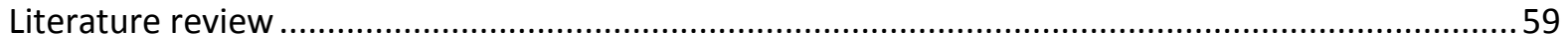

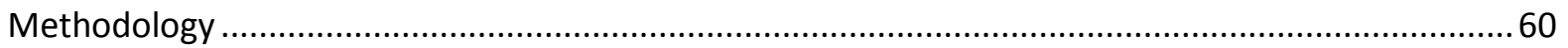

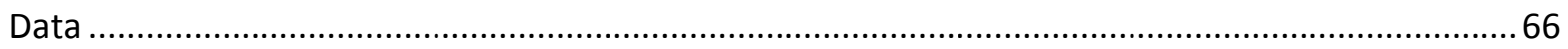

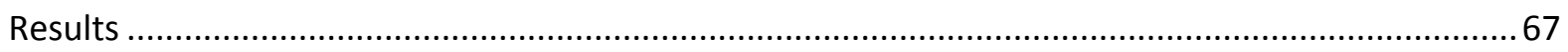

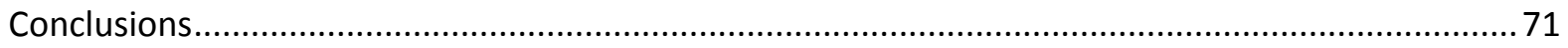

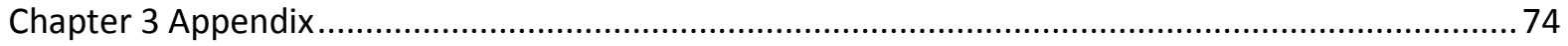

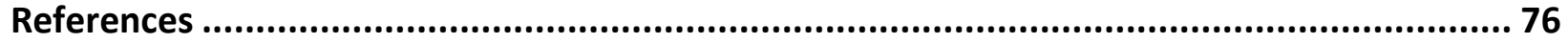




\section{List of Figures and Tables}

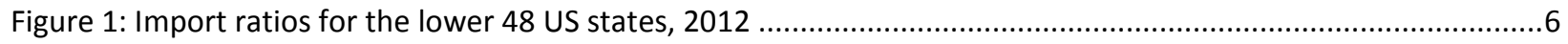

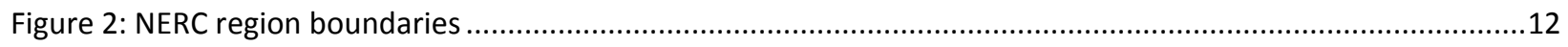

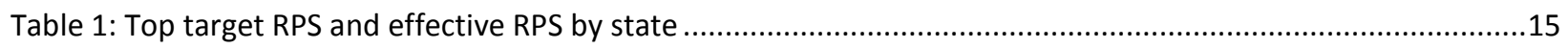

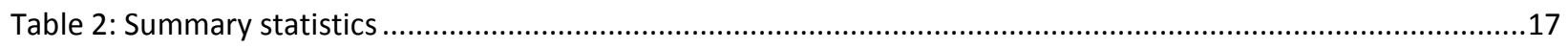

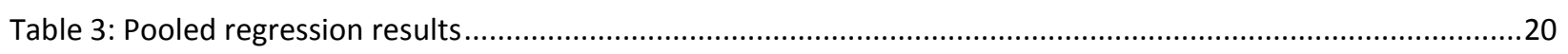

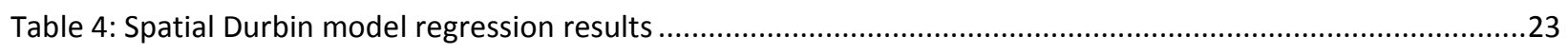

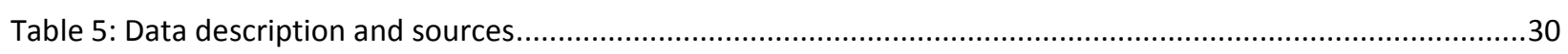

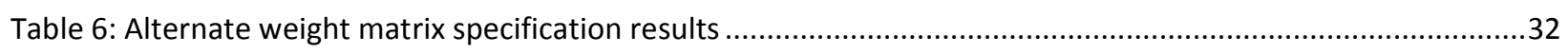

Table 7: Ramp rates and variable costs by generating technology ..................................................................

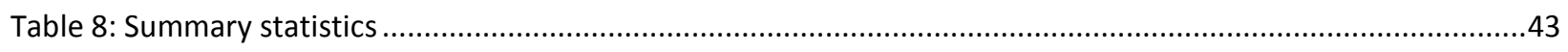

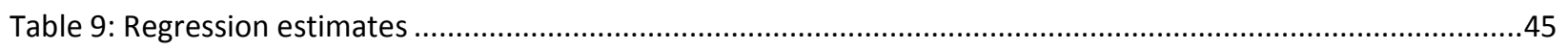

Figure 3: System capacity utilization by prime mover technology and year .........................................................51

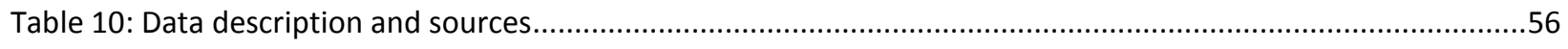

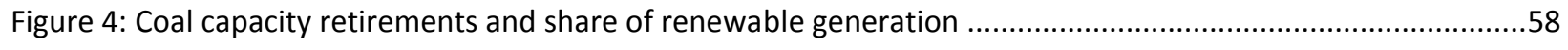

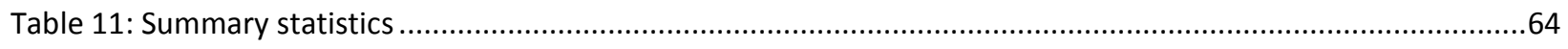

Table 12: Logit regression estimates .........................................................................................................6

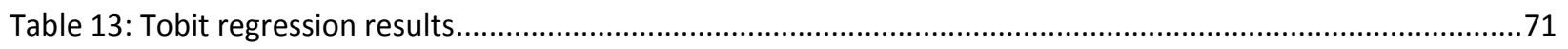

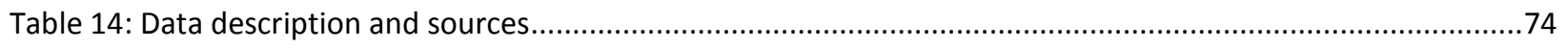




\section{Introduction}

In the last decade or so, renewable energy has gone from being a small fraction of electricity generation in the United States to becoming a significant source of energy for consumers. Since 2001, the share of electricity generation produced by non-hydro renewable sources has more than doubled, rising from 3.2 percent in 2001 to more than 6.9 percent in 2014 (EIA 2014b). This rapid gain in market share has been driven in large part by federal and state policies designed to subsidize renewable energy in an effort to reduce carbon output and promote other environmental aims.

In this dissertation, I investigate the effectiveness of renewable policies and consider their impact on electricity markets. The common thread of this research is to understand how renewable policy incentivizes renewable generation and how the increasing share of generation from renewables affects generation from fossil fuels. This type of research is crucial for understanding whether policies to promote renewables are meeting their stated goals and what the unintended effects might be. To this end, I use primarily an empirical approach to examine how electricity markets are responding to an influx of renewable energy.

My dissertation is composed of three interrelated essays; in the following sections, I give a brief overview of each chapter. In Chapter 1, I employ recent scholarship in spatial econometrics to assess the spatial dependence of Renewable Portfolio Standards (RPS), a prominent state-based renewable incentive. In Chapter 2, I explore the impact of the rapid rise in renewable generation on short-run generation from fossil fuels. And in Chapter 3, I assess the impact of renewable penetration on coal plant retirement decisions. 


\section{Chapter 1}

In my first essay, I explore how spatial dependence affects electricity markets for renewable power. In particular, I examine renewable portfolio standards - policies that mandate a percentage of electric generation must come from renewable sources - which have been widely adopted across the United States. A number of studies have attempted to ascertain whether RPS policies have been effective at increasing renewable energy in the states that adopt them. Most of the recent literature has found little impact from RPS policies on either renewable capacity or generation in RPS states. However, because electricity can travel over a wide geographical area across multiple state boundaries, spatial interactions among states are likely affecting the impact of RPS policies on renewable energy markets.

As far as I am aware, none of the existing literature has examined in a rigorous econometric context the spatial interactions of RPS policies on surrounding states. Thus this paper's primary contribution is to examine spatial dependence in electricity markets to determine whether RPS laws have been effective in increasing generation from renewables on a systemwide basis. I find evidence that while stronger RPS laws have a small or even negative impact on within-state renewable generation, they have a positive impact on total renewable generation within a NERC region as a whole once I account for spatial dependence among states. This research indicates that the spillover effect of a given state's RPS law on surrounding states is an important measure of these laws' effectiveness in promoting renewable adoption.

\section{Chapter 2}

In this essay, I investigate the effects of renewable policy on fossil fuel generation. Several economic and theoretical models have predicted that strict renewables laws will cause a replacement of natural gas generation in the market with renewable generation. However, a 
number of industry analysts have described the importance of natural gas as a backup fuel for intermittent renewable generation. This would suggest a complementarity between the two types of fuels, which would indicate that as renewables represent a rising share of power generation, natural gas should also increase.

I seek to evaluate these largely theoretical assessments by applying econometric techniques to plant- and unit-level generation and cost data to measure the effect of increased penetration of renewables on dispatch rates of individual generating units. My results give conflicting evidence about which of these literatures is correct. Surprisingly, I find no evidence that renewable generation is complementary to natural gas generation in terms of encouraging greater output from existing plants. My results show no significant effects of renewable penetration on capacity factors of natural gas combined cycle plants, and I find that renewables are associated with significantly reduced capacity factors for natural gas combustion turbines. I also find that as renewables become a larger share of power generation, generating units powered by coal are used more intensively.

\section{Chapter 3}

Retirements of coal-fired electric generating capacity have become an increasing concern for policy makers in US electricity markets. Between 2011 and 2013, a total of almost 20 gigawatts of coal-fired capacity was retired, representing nearly 6 percent of the total capacity in that period. The US Energy Information Administration projects that by 2020 another 50 gigawatts of coal-fired capacity could be retired, representing about 15 percent of the total coalfired capacity in operation as of the end of 2013 (EIA 2014a).

This chapter examines several potential drivers of coal capacity retirements to estimate which are most prominent empirically, with a particular focus on renewable penetration on a 
NERC region level. This research in part stems from previous findings in Chapter 2 that renewable penetration is associated with increases in capacity factors for coal-fired power plants. I find that the drivers of coal plant retirements are multi-faceted, stemming from changes in federal environmental policy as well as variation in the price of competing fuels. However, consistent with results in the previous chapter, I find that renewable penetration in a plant's NERC region reduces the likelihood of plant retirements. 


\title{
Chapter 1: Spatial dependence of Renewable Portfolio Standards and their effect on renewable generation within NERC regions
}

\begin{abstract}
While several studies have examined the effectiveness of renewable portfolio standard laws on renewable generation in states, previous literature has not assessed the potential for spatial dependence in these policies. Spatial dependence in the electric grid is likely, considering the connectivity of the electric grid across NERC regions. Using recent spatial panel methods, this paper estimates a number of econometric models to examine the impact of RPS policies when spatial autocorrelation is taken into account. Consistent with previous literature, I find that RPS laws do not have a significant impact on renewable generation within a state. However, I find evidence that a state's RPS laws have a significant positive impact on the share of renewable generation the NERC region as a whole. These findings provide evidence that electricity markets are efficiently finding the lowest-cost locations to serve renewable load in states with more stringent RPS laws.
\end{abstract}

\section{Introduction}

Renewable portfolio standards (RPS) have been widely adopted across the United States, and a number of studies have attempted to ascertain whether they have been effective at increasing renewable energy in the states that adopt the policies. With the exception of Yin and Powers (2010), most of the recent literature has found little impact from RPS policies on either renewable capacity or generation in RPS states. However, because electricity can travel over a wide geographical area across multiple state boundaries, spatial interaction among these state policies are crucial to understanding renewable energy markets. Efficient electricity markets rely on the ability of generators to sell power into a large spatial area and for least-cost plants to be dispatched across the dispatch region. Indeed, properly functioning electricity markets should show significant spatial interactions as renewable generation facilities are built in the most efficient locations for generating electricity, which can then be transmitted to load centers that are often hundreds of miles away. Figure 1 shows the import ratios of each state in 2012, which are calculated as the difference between electricity sales and generation as a share of sales. 
Negative numbers indicate states that export electricity, as they produce more than the demand in that state. As is evident in the map, exporting states are highly clustered with importing states, particularly in the load centers of the northeast and California, illustrating the interdependency of states in the electric grid.

\section{Figure 1: Import ratios for the lower 48 US states, 2012}

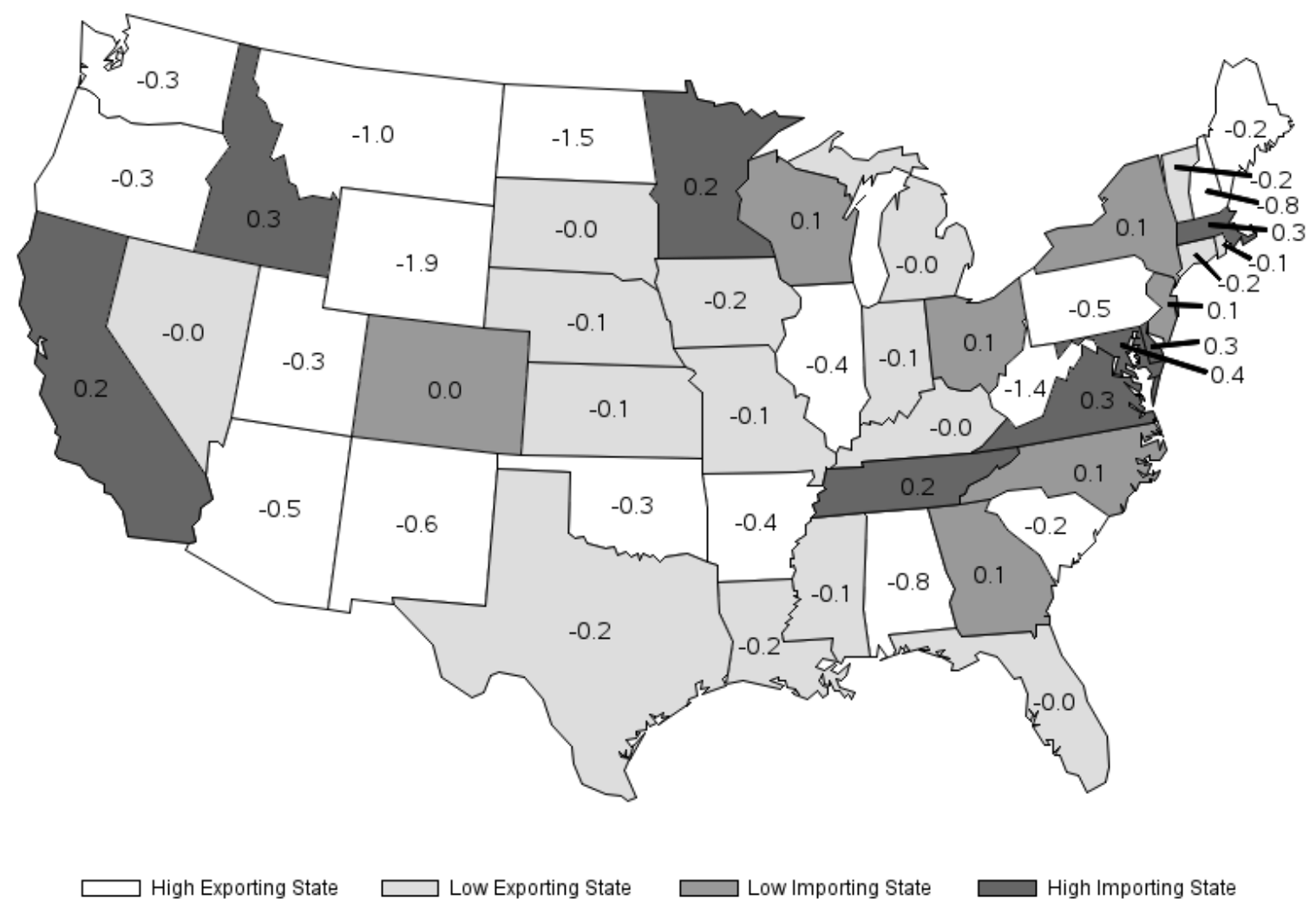

As far as I am aware, none of the existing literature has examined in a rigorous econometric context the spatial interactions of RPS policies on surrounding states. Thus this paper's primary contribution is to examine spatial dependence in electricity markets to determine whether RPS laws have been effective in increasing generation from renewables on a systemwide basis. My hypothesis is that once spatial dependence is taken into account, I will find that stronger RPS laws will increase renewable generation within a NERC region as a whole. Indeed, 
my results show that while stronger RPS laws have a small or even negative impact on withinstate renewable generation, they have a positive impact on total renewable generation within a NERC region once I account for spatial dependence among states. This research indicates that the spillover effect of a given state's RPS law on surrounding states is an important measure of these laws' effectiveness in promoting renewable adoption. I believe this is the first study to examine these spillover effects in a systematic way.

\section{Background and literature review}

Renewable Portfolio Standard rules require a percentage of energy sold or generated in a state to come from renewable sources, such as wind, solar or geothermal power. The first Renewable Portfolio Standard law was enacted in Iowa in 1983, and many other states followed suit in the late 1990s and later. As of the end of 2012, 29 states and the District of Columbia had adopted mandatory targets for renewable electricity generation, and seven other states had adopted voluntary goals. ${ }^{1}$ RPS laws typically set a target for a percentage of electricity demand in a state to be met by renewables by a particular date, usually between 10-20 years after adoption of the policy. In most cases, the laws set intermediate targets that must be met before the final target year. For example, California adopted an RPS in 2002 that mandated 33 percent of electricity sales come from renewable sources by 2020, with intermediate targets of 20 percent by 2013 and 25 percent by 2016 (DSIRE 2012).

Early RPS studies (see for example Smith, Grace, and Wiser 2000, Gouchoe, Everette, and Haynes 2002, Chen et al. 2003, Moseidjord 2004, Langniss and Wiser 2003) were primarily case studies of individual states' policies and found varying compliance with the RPS laws. Menz

\footnotetext{
${ }^{1}$ Until repealed in 2015, West Virginia's standard was mandatory but could be met with fossil fuel generation and thus was classified as voluntary by the Database of State Incentives for Renewables and Efficiency (DSIRE 2012).
} 
and Vachon (2006) was the first to examine RPS policies using multivariate econometric techniques and found that RPS policies had a positive impact on renewable electricity capacity. However, Menz and Vachon's methodology was challenged by later researchers (see Michaels 2008, Wiser et al. 2007, Carley 2009, Shrimali and Kniefel 2011), who found that RPS policies had little effect on the share of renewables in the fuel mix of the state where they were enacted.

RPS policies vary considerably on a number of characteristics, including the stringency of the percentage requirement, how much generation capacity is required to meet the standard, and what types of renewables are allowed to meet the requirements. This variability in the standard has posed difficulties for determining whether the policies have been effective in promoting adoption of renewable technologies. To account for some of these differences, Yin and Powers (2010) introduced a new measure of the strength of each state's RPS policies, which they termed the incremental percentage requirement. Using this measure, the authors found that RPS policies had a significant positive impact on in-state capacity investment. Wiser, Barbose, and Holt (2011), found that RPS standards have been important drivers of investment in solar technologies. However, Shrimali et al (2012) found that the Yin and Powers study suffered from data errors, and concluded that after accounting for these problems RPS policies had little effect on renewable capacity.

\section{Methodology}

The influence of spatial dependence in RPS policies on the electric grid has not been previously studied in the existing literature relating to these policies. Spatial dependence exists when the values observed in one spatial location are dependent on the values in neighboring locations (LeSage and Pace 2009). In the case of the electric grid, reliability is overseen by the

North American Electric Reliability Corporation (NERC), which has defined eight regions in the 
lower 48 US states where electricity is shared extensively. ${ }^{2}$ Balancing authorities within each NERC region are interconnected so that power can be generated and sold across a wide geographical area in order to both dispatch the lowest-cost generation and to maintain reliability in the grid. Because of this interconnected structure of the electric grid, it is likely that electricity markets exhibit spatial dependence. Both Shrimali (2012) and Yin and Powers (2010) attempted to address effects of contiguous states' RPS standards, but neither specify a spatial econometric model. However, other studies have found significant spatial dependence in electricity markets. Douglas and Popova (2011), for example, modeled electricity prices using a spatial error model, finding that spatial econometric methods improve electricity price forecasts. And Burnett and Zhao (2014) found spatial dependence in an examination of transmission constraints. For these reasons, I believe there is considerable evidence for spatial dependence in the electric grid and that should be considered when evaluating RPS policies.

This paper intends to show how spatial interactions among states within a NERC region affect renewable generation in contiguous states. I specify multiple spatial econometric models relating the renewable share of generation with a measure of the strength of RPS policies. These models regress the share of renewable generation (RENSHARE_GEN) of state $i$ in time $t$ as a function of its effective RPS (EFFRPS) and other control variables. I also include time and space fixed effects. Following notation in Elhorst (2014), I define the general nested spatial panel model as follows:

$$
\begin{aligned}
& Y_{i t}=\rho W_{t} Y_{i t}+X_{i t} \beta+W_{t} X_{i t} \theta+\mu_{i}+\xi_{t} \iota_{N}+u_{t} \\
& u_{t}=\lambda W_{t} u_{t}+\varepsilon_{t}
\end{aligned}
$$

\footnotetext{
${ }^{2}$ Because of their geographical remoteness, Alaska and Hawaii are not connected to the rest of the electric grid, and operate as their own NERC regions. These states are not considered in this study.
} 
This nested specification allows for the potential of a spatial lag term on the dependent variable $(\rho)$, a spatially lagged error term $(\lambda)$, as well as a spatial lag on the $\mathrm{X}$ variables $(\theta)$. I define $\mu_{i}$ as spatial specific effects, and $\xi_{t}$ as time-period specific effects. In this context, if all spatial terms are zero (i.e. $\rho=\theta=\lambda=0$ ), then the model becomes a standard fixed effects panel model. Once spatial dependence is introduced, standard panel models have to be modified to include the potential for spatial autocorrelation. Various spatial models can be specified depending on which spatial terms are assumed to be present in the data generating process. If the assumption is made that $\rho=0$ and $\theta=0$, this is termed a spatial error model (SEM) that accounts for spatial autocorrelation in the error term only. If it is assumed that $\lambda=0$ and $\theta=0$, then the general model becomes a spatial autoregressive model (SAR), which models spatial autocorrelation in the dependent variable only. Making the assumption that $\rho=0$ and $\theta \neq 0$, indicates a spatially lagged X model (SLX). And lastly, if $\lambda=0$ alone, then the general models becomes a spatial Durbin model (SDM), which is a SAR model with spatially-weighted explanatory variables. In each type of model, the spatially weighted variables are multiplied by a spatial weight matrix that results in a weighted average of the neighboring spatial units. A typical spatial weight matrix represents the contiguity of each spatial unit with neighboring units based on some measure of distance. Each entry in the matrix consists of a 1 for those other units that are neighbors with the given spatial unit, and zeros for other units. The diagonal entries are zero by convention because a geographic unit cannot be a neighbor to itself. This forms a square symmetric matrix with dimensions equal to the number of spatial units that is then rownormalized. In a spatial panel context, the weight matrix is a block diagonal matrix with sections for each time period and zeros in the rest of the matrix. For example, in the SAR model, the dependent variable is multiplied by the weight matrix, which adds a new regressor that is the 
average of the dependent variables for that state's neighbors. This allows me to take into account the effects of neighboring states on each individual state. In the SDM model, I also take into account potential spatial dependence among the independent variables by including a weighted average of each independent variable from contiguous states.

Spatial contiguity in this paper is defined by each state's NERC region. I have assumed first that if a state lies at least partially within a NERC region with another state, it is considered a neighbor to that state. As Figure 2 shows, NERC regions cross multiple state boundaries, and thus some border states may be neighbors with states in multiple NERC regions. As an example, Minnesota falls entirely within the boundaries of the Midwest Reliability Organization (MRO), and thus would be considered contiguous only with North Dakota, South Dakota, Nebraska, Iowa, and Wisconsin. However, South Dakota also falls partially within the Western Electricity Coordinating Council (WECC), and would thus be contiguous with the 11 other states in that region, in addition to those in the MRO. Second, unlike in many spatial contexts where contiguity is fixed, in this study the weight matrix changes over time to fit the NERC region map in each year of data. There have been two major NERC region realignments during the time period of this study. Also, utilities have changed affiliation with dispatch organizations and NERC councils as their needs changed. 
Figure 2: NERC region boundaries

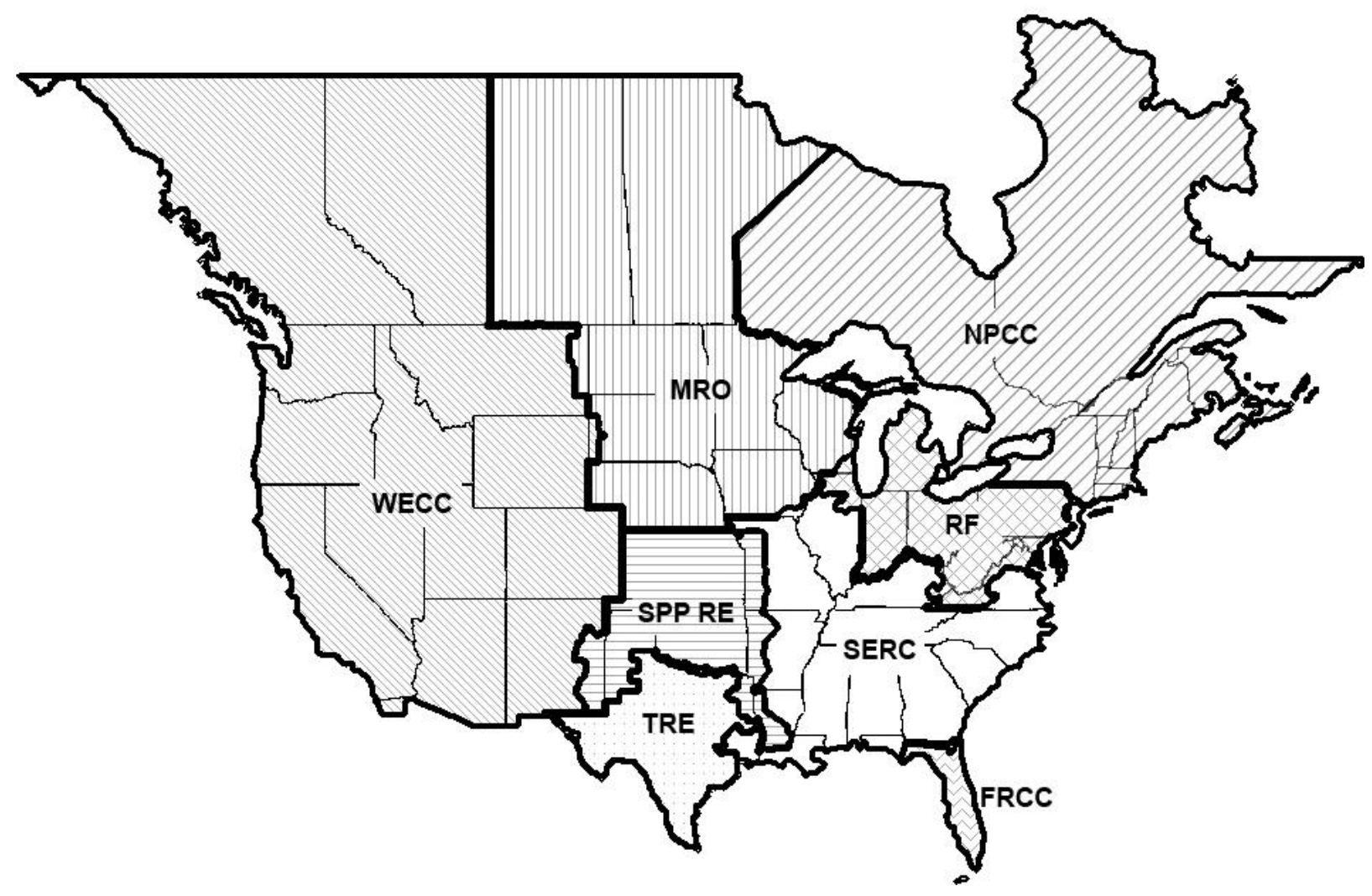

As shown in equation (3), the dependent variable (RENSHARE_GEN) is defined as the percentage of total generation in state $i$ in year $t$ that was renewable.

$$
\text { RENSHARE_GEN }_{i t}=\frac{\text { Renewable Generation }_{i t}}{\text { Total Generation }}
$$

I choose to focus on generation rather than capacity primarily because generation flows across state boundaries, and some capacity may be built in one state to serve load in neighboring states. As mentioned above, Shrimali et al (2012), identified data errors in the Yin and Powers (2010) paper that they concluded accounted for the positive association between the RPS laws and increased renewable capacity. Shrimali indicate that prior to 2001, the US EIA reported plant-level data only for utilities on form EIA-906, which Yin and Powers used in their analysis. Shrimali included non-utility data from EIA form 867, and EIA form 906 non-utility. Once data 
from non-utilities was included in the analysis, the impact of RPS laws disappeared. Shrimali recommended using aggregate state-level data, which does include non-utility data. Because of this finding, I use the EIA's Detailed State Data (EIA 2012c, b) to calculate the generation shares, as well as the effective RPS defined below.

The primary independent variable for equation (1) is a measure of the strength of a state's renewable portfolio standard. Following Yin and Powers (2010), I define EFFRPS, as the effective RPS in each state, which may be different than the nominal RPS written into state law because of each state's particular blend of exceptions and coverage requirements. ${ }^{3}$ The variable is calculated as follows:

$$
\text { EFFRPS }_{i t}=\text { Nominal }_{i t} \times \text { Coverage }_{i t}-\frac{\text { Existing }_{i 0}}{\text { Sales }_{i 0}}
$$

In this formulation, Nominal is defined as the target RPS requirement in state $i$ in year $t$. This variable reflects the current-year RPS target written into each state's law. I use data provided in the Database of State Incentives for Renewables and Efficiency (DSIRE 2012) December 2012 data release for this variable. States have different requirements for which load servicing entities (LSEs) must meet the standard, which typically breaks down by corporate ownership. Thus Coverage is defined as the percentage of sales that is covered by the RPS at time $t$, based on which load servicing entities (LSEs) - typically utilities - are required to meet the standard in individual state $i$. Coverage requirements are calculated using EIA-861 (EIA 2012a) using the covered utility definitions found in the DSIRE database. Existing is the amount of energy generated in each state (hereafter "existing generation") that is allowed by law to be counted toward the RPS standard at time zero, which is the date the RPS became effective in that state.

\footnotetext{
${ }^{3}$ Yin and Powers name this variable the incremental percentage requirement (INCRQMTSHARE).
} 
Definitions of which renewables count toward the standard are taken from the DSIRE database and the generation and capacity data are taken from EIA Detailed State Data (EIA 2012c, b). States have a variety of rules for how much of existing generation is allowed to be counted toward the standard. Some states allow only new generation to be counted, while others allow some or all existing generation to count toward the RPS requirements. I account for these differences when calculating existing generation. Lastly, Sales is total electricity sales in the state at the time the RPS standard went into effect, and is taken from EIA Detailed State Data (EIA 2012d). It is unclear how Yin and Powers handle those states (Iowa and Texas) with capacity standards instead of sales standards. Since capacity is measured in MW, and sales are measured in MWh, it is necessary to keep like units together for the purposes of calculating the nominal and coverage requirements. For these states I have calculated the nominal and coverage requirements by dividing renewable capacity in the year the RPS law was enacted by total capacity. I use capacity data from EIA's Detailed State Data (EIA 2012b) for both the numerator and denominator for these states. This calculation ensures comparable units for nominal percentage requirements with those based on sales percentages. Combining units leaves two percentages. The first term in the definition is the percent of generation to which the RPS applies given the LSEs covered by the standard. The second term represents the proportion of existing renewable generation allowed to be counted toward the RPS standard. Thus EFFRPS measures the percentage of new generation required by the RPS beyond the existing renewable generation, which I take to be a measure of the strength of the RPS to incentivize additional renewable generation. The EFFRPS values for each state with an RPS are listed in Table 1. 
Table 1: Top target RPS and effective RPS by state

\begin{tabular}{|c|c|c|c|c|c|}
\hline State & Top EFFRPS & RPS Target & State & Top EFFRPS & RPS Target \\
\hline AK & $0.0 \%$ & $0.0 \%$ & MT & $10.9 \%$ & $15.0 \%$ \\
\hline AL & $0.0 \%$ & $0.0 \%$ & $\mathrm{NC}^{\dagger}$ & $11.9 \%$ & $12.5 \%$ \\
\hline AR & $0.0 \%$ & $0.0 \%$ & ND $^{*}$ & $9.8 \%$ & $10.0 \%$ \\
\hline AZ & $8.7 \%$ & $15.0 \%$ & NE & $0.0 \%$ & $0.0 \%$ \\
\hline CA & $13.3 \%$ & $33.0 \%$ & NH & $17.4 \%$ & $24.8 \%$ \\
\hline $\mathrm{CO}^{\dagger}$ & $18.1 \%$ & $30.0 \%$ & NJ & $18.1 \%$ & $22.5 \%$ \\
\hline CT & $15.6 \%$ & $27.0 \%$ & $\mathrm{NM}^{+}$ & $13.8 \%$ & $20.0 \%$ \\
\hline DE & $24.3 \%$ & $25.0 \%$ & NV & $5.4 \%$ & $25.0 \%$ \\
\hline FL & $0.0 \%$ & $0.0 \%$ & NY & $0.1 \%$ & $29.0 \%$ \\
\hline GA & $0.0 \%$ & $0.0 \%$ & $\mathrm{OH}^{*}$ & $11.0 \%$ & $25.0 \%$ \\
\hline HI & $33.3 \%$ & $40.0 \%$ & $\mathrm{OK}^{*}$ & $15.0 \%$ & $15.0 \%$ \\
\hline IA & $0.0 \%$ & $1.2 \%$ & $\mathrm{OR}^{\dagger}$ & $7.5 \%$ & $25.0 \%$ \\
\hline ID & $0.0 \%$ & $0.0 \%$ & $\mathbf{P A}^{*}$ & $13.7 \%$ & $18.0 \%$ \\
\hline IL & $22.5 \%$ & $25.0 \%$ & RI & $14.5 \%$ & $16.0 \%$ \\
\hline IN* & $8.0 \%$ & $10.0 \%$ & SC & $0.0 \%$ & $0.0 \%$ \\
\hline KS & $12.0 \%$ & $20.0 \%$ & SD* $^{*}$ & $9.7 \%$ & $10.0 \%$ \\
\hline KY & $0.0 \%$ & $0.0 \%$ & TN & $0.0 \%$ & $0.0 \%$ \\
\hline LA & $0.0 \%$ & $0.0 \%$ & $\mathrm{TX}^{\ddagger}$ & $3.2 \%$ & $8.7 \%$ \\
\hline MA & $20.8 \%$ & $22.1 \%$ & UT* & $20.0 \%$ & $20.0 \%$ \\
\hline MD & $14.9 \%$ & $20.0 \%$ & $\mathrm{VA}^{*}$ & $6.1 \%$ & $15.0 \%$ \\
\hline ME & $8.2 \%$ & $40.0 \%$ & $\mathrm{VT}^{*}$ & $20.0 \%$ & $20.0 \%$ \\
\hline MI & $6.6 \%$ & $10.0 \%$ & WA & $11.2 \%$ & $15.0 \%$ \\
\hline $\mathrm{MN}^{\dagger}$ & $21.9 \%$ & $31.5 \%$ & WI & $4.7 \%$ & $10.0 \%$ \\
\hline MO & $10.5 \%$ & $15.0 \%$ & $w^{*}$ & $24.8 \%$ & $25.0 \%$ \\
\hline MS & $0.0 \%$ & $0.0 \%$ & WY & $0.0 \%$ & $0.0 \%$ \\
\hline
\end{tabular}

The control variables are as follows. First, since strict RPS laws are more likely to be passed in those states with high support for environmentalism, I control for environmental feeling among the state's residents. To measure environmentalism, I define LCVSCORE as the average score on the League of Conservation Voters Scorecard (LCV 2013). The LCV assigns a score to each national legislator depending on how closely they vote in the interests of the League. I take an average of all legislators in a state to derive the average state score. The use of LCV scores as a measure of environmentalism is common in the RPS literature (for example 
Carley 2009, Yin and Powers 2010, Shrimali et al. 2012). I would expect there is a positive relationship between a state's environmental score and that state's share of renewable generation. Second, I control for a state's energy import ratio (IMPORTRATIO), which is calculated as sales of electricity minus generation as a share of sales. The import ratio is positive if a state consumes more electricity than it generates, and negative if it exports electricity. The data for this variable is taken from the EIA Detailed State Data (EIA 2012c, d). I expect that higher import ratios would be associated with higher levels of renewable generation, because those states are not as dependent on fossil fuels, except through their imports. I control for the state's median income (MEDINCOME) (taking the logarithm), as reported by the US Census Bureau (2012). I expect that higher income levels will be associated with higher levels of renewables, as these states are more likely to be willing to pay for the higher energy costs associated with renewable generation. In addition to median income, I control for the average electricity price (AVGELECPRICE), which I expect to be positively associated with renewable generation because renewable generation is generally more expensive. I also control for the presence in each state of three alternative policies for promoting renewable generation: the presence of a public benefit fund $(P B F)$, net metering (NETMETER), and a mandatory green power option (MANDGREEN). Public benefit funds typically add a small surcharge on customers' bills to fund renewable energy projects, energy efficiency programs and/or renewable research. Net metering allows utility customers to sell excess power generated by the customer back to the electricity grid, usually at the full electricity rate faced by the customer. It is used primarily by customers who have installed solar panels at their locations. Mandatory green power option laws require utilities to offer consumers the choice to have their power supplied by renewable energy. This gives consumers the ability to purchase renewable power if they want it, typically at a higher price 
than fossil-fuel based power. The data for these variables is taken from DSIRE (2012). As with the portfolio standard, I expect these policies to be positively associated with a higher share of renewable generation. Lastly, I include in some specifications a binary variable for whether a state's RPS policy is a requirement or a goal (RPSMANDATE). I expect that mandatory policies will be more likely to be associated with higher renewable generation.

I exclude Alaska and Hawaii, as these states' power grids are not tied to any other state. The final dataset is a balanced panel of 48 states for the years 1990 through 2012. Summary statistics for all variables are given in Table 2.

Table 2: Summary statistics

\begin{tabular}{lcccccc}
\hline \multicolumn{1}{c}{ Variable } & $\begin{array}{c}\text { Number of } \\
\text { Observations }\end{array}$ & Mean & $\begin{array}{c}\text { Standard } \\
\text { Deviation }\end{array}$ & Median & Minimum & Maximum \\
\hline RENSHARE_GEN & 1,104 & 3.10 & 4.55 & 1.90 & 0.00 & 37.14 \\
EFFRPS & 1,104 & 0.25 & 0.99 & 0.00 & 0.00 & 9.11 \\
EFFRPSTOP & 1,104 & 3.72 & 6.68 & 0.00 & 0.00 & 24.81 \\
AVGELECPRICE & 1,104 & 7.59 & 2.50 & 6.90 & 3.37 & 18.06 \\
LCVSCORE & 1,104 & 47.59 & 24.64 & 45.13 & 0.00 & 100.00 \\
IMPORTRATIO & 1,104 & -0.25 & 0.60 & -0.11 & -3.04 & 0.83 \\
PBF & 1,104 & 0.20 & 0.40 & 0.00 & 0.00 & 1.00 \\
NETMETER & 1,104 & 0.48 & 0.50 & 0.00 & 0.00 & 1.00 \\
MANDGREEN & 1,104 & 0.05 & 0.22 & 0.00 & 0.00 & 1.00 \\
MEDINCOME & 1,104 & 10.85 & 0.15 & 10.85 & 10.41 & 11.20 \\
RPSMANDATE & 1,104 & 0.58 & 0.49 & 1.00 & 0.00 & 1.00 \\
\hline
\end{tabular}

\section{Results}

The results of several pooled model specifications are shown in Table 3 . It is clear from these results that the data show significant spatial dependence in all three spatial models shown here. This is indicated from the positive significant coefficients on the $\lambda$ term in the SEM model and $\rho$ term in the SAR models. The $\rho$ term is not significant in the SDM model; however, the effects estimates for the SDM model show significance in the indirect effects, indicating spatial dependence in the independent variables. The coefficient estimates are similar in most of the 
pooled specifications. All of the models show a statistically significant negative coefficient for the primary variable of interest - EFFRPS. These results are similar in interpretation to many of the model specifications in Shrimali (2012).

As LeSage and Pace (2009) point out, the marginal effects of a spatial model are not equivalent to the coefficient estimates themselves (i.e. the $\beta \mathrm{s}$ ), but require adjustment to account for spatial interaction. In the SDM model, for example, I can solve the reduced form equation as follows:

$$
\left(I_{k N}-\rho W\right) y=X \beta+W X \theta+\varepsilon
$$

yielding the following marginal effect for each of the $\mathrm{X}$ variables $\left(x_{r}\right)$ :

$$
\frac{\partial y}{\partial x_{r}}=\left(I_{k N}-\rho W\right)^{-1}\left[I_{k N} \beta_{r}+W \theta_{r}\right]
$$

The marginal effects for each variable are thus a $(k \cdot N \times k \cdot N)$ matrix of effects estimates, where $k$ is the number of time periods and $N$ is the number of spatial units. The effects estimates are calculated using the entire weight matrix, making them an average of the marginal effects across all time periods. LeSage and Pace recommend categorizing the marginal effects into direct effects and indirect (or spillover) effects and calculating the mean of each of these effects estimates. The direct effect is thus calculated by taking the trace of the marginal effects matrix and dividing by the number of observations, yielding the marginal effect on the state of each independent variable on its own renewable generation share. The indirect or spillover effect is the mean of the off-diagonal elements of the marginal effects matrix, which provides the marginal effect of changes in independent variables in contiguous states on the primary state. The total effect is the sum of the two and represents the marginal effect if I take into account the changes in independent variables for both the individual state and its neighbors. 
In the context of this study, the marginal effects of the spatial models have a specific economic meaning. The direct effect coefficient of the primary policy variable is the effect of each state's RPS law on its own renewable generation. This is similar in interpretation, though not directly comparable numerically, to the marginal effects coefficients in previous literature that examined how RPS laws affect renewable penetration. The indirect effect can be interpreted as how the RPS laws in other states within a region affect the renewable generation of a given state. In other words, it would indicate how RPS laws in the WECC region, for example, would affect renewable generation in one of its member states.

As shown in Table 3, the total impact of the SAR model and the SEM model are similar, with a negative significant coefficient on EFFRPS. In the SAR model, the indirect effects are positive, but not significant, giving a significant, but still negative total effect. However, the effects estimate for the SDM model gives a different picture. The indirect effect in the SDM model is positive and larger than the direct effect, which is not surprising given that the indirect effects are cumulative across all neighbors. The total effect is significant and positive. 
Table 3: Pooled regression results

\begin{tabular}{|c|c|c|c|c|c|}
\hline \multicolumn{6}{|c|}{ Dependent variable: RenShare_Gen } \\
\hline & & $\begin{array}{l}\text { Model 1: } \\
\text { OLS }\end{array}$ & $\begin{array}{c}\text { Model 2: } \\
\text { SEM }\end{array}$ & $\begin{array}{c}\text { Model 3: } \\
\text { SAR }\end{array}$ & $\begin{array}{l}\text { Model 4: } \\
\text { SDM }\end{array}$ \\
\hline \multirow{10}{*}{$\begin{array}{l}\text { Direct } \\
\text { Effect }\end{array}$} & EFFRPS & $-0.454(0.001)$ & $-0.571(0.000)$ & $-0.438(0.002)$ & $-0.612(0.000)$ \\
\hline & AVGELECPRICE & $0.586(0.000)$ & $0.521(0.000)$ & $0.527(0.000)$ & $0.358(0.000)$ \\
\hline & IMPORTRATIO & $0.665(0.002)$ & $0.382(0.001)$ & $0.413(0.056)$ & $0.668(0.003)$ \\
\hline & LCVSCORE & $0.004(0.531)$ & $0.001(0.826)$ & $-0.001(0.830)$ & $-0.001(0.877)$ \\
\hline & MANDGREEN & $3.799(0.000)$ & $0.005(0.000)$ & $3.754(0.000)$ & $3.270(0.000)$ \\
\hline & NETMETER & $1.798(0.000)$ & $6.928(0.000)$ & $1.530(0.000)$ & $1.707(0.000)$ \\
\hline & PBF & $0.046(0.905)$ & $0.735(0.315)$ & $-0.003(0.993)$ & $0.429(0.276)$ \\
\hline & MEDINCOME & $-4.374(0.000)$ & $-4.571(0.000)$ & $-0.152(0.001)$ & $-4.153(0.000)$ \\
\hline & Lambda & & $0.286(0.000)$ & & \\
\hline & Rho & & & $0.26(0.000)$ & $0.149(0.955)$ \\
\hline \multirow{8}{*}{$\begin{array}{l}\text { Indirect } \\
\text { Effect }\end{array}$} & EFFRPS & & & $-0.016(0.597)$ & $1.443(0.000)$ \\
\hline & AVGELECPRICE & & & $0.018(0.606)$ & $0.498(0.008)$ \\
\hline & IMPORTRATIO & & & $0.016(0.606)$ & $-2.607(0.024)$ \\
\hline & LCVSCORE & & & $0.000(0.904)$ & $0.028(0.128)$ \\
\hline & MANDGREEN & & & $0.135(0.588)$ & $2.456(0.212)$ \\
\hline & NETMETER & & & $0.053(0.600)$ & $-2.929(0.002)$ \\
\hline & PBF & & & $-0.001(0.976)$ & $-3.225(0.012)$ \\
\hline & MEDINCOME & & & $-0.005(0.614)$ & $6.195(0.028)$ \\
\hline \multirow{8}{*}{ Total Effect } & EFFRPS & & & $-0.455(0.002)$ & $0.830(0.025)$ \\
\hline & AVGELECPRICE & & & $0.544(0.000)$ & $0.856(0.000)$ \\
\hline & IMPORTRATIO & & & $0.429(0.060)$ & $-1.939(0.113)$ \\
\hline & LCVSCORE & & & $-0.001(0.829)$ & $0.027(0.152)$ \\
\hline & MANDGREEN & & & $3.889(0.000)$ & $5.726(0.005)$ \\
\hline & NETMETER & & & $1.582(0.000)$ & $-1.221(0.213)$ \\
\hline & $P B F$ & & & $-0.004(0.992)$ & $-2.796(0.034)$ \\
\hline & MEDINCOME & & & $-0.157(0.001)$ & $2.042(0.461)$ \\
\hline
\end{tabular}

Note: Coefficients reported here are the marginal effects. P-values are in parenthesis.

Given that these data show spatial dependence, model choice can be somewhat difficult. Under most circumstances, LeSage and Pace (2009) suggest specifying an SDM model, since it takes into account spatial dependence among the dependent and independent variables. The SDM model has the added benefit of having both the SAR and SLX models nested within its specification. It collapses to the SAR model if the $\theta$ terms on the $\mathrm{X}$ variables are not significant, or the SLX model if $\rho$ is not significant, as is the case here. Estimating an SDM model is also 
appropriate if there are omitted variables that are spatially correlated and correlated with an included explanatory variable. Also, in the SAR model, the effects estimates are constrained to be of the same sign, which is not the case in the SDM model. In the context of this study, I prefer the SDM model, as it allows the examination of the impact of RPS laws within a region on member states, which is the key question I am trying to address. This choice is justified by the econometric results. The spatial lag term $(\rho)$ is significant in the SAR model, but not the SDM model; however the $\theta$ coefficients, including that for my primary variable of interest, are mostly significant, indicating that there is spatial interaction in the independent variables. Also, since the SAR model is nested within the SDM model, I can perform a likelihood ratio test. The LR test indicates that the SDM and SAR models are significantly different from one another, lending credence to the choice of the SDM model as the preferred model in this case.

\section{SDM Model specifications}

After choosing the SDM model, I specify multiple spatial Durbin panel models. These models take advantage of recent scholarship in the spatial econometrics literature to account for space and time unobserved effects in the regression specification. These results are shown in

Table 4. Model 1 repeats the pooled SDM results from above. Models 2 through 4 report the results for spatial panel models with fixed effects for space and time. Lee and Yu (2010) demonstrate how to correct for biased estimators when using fixed effects in a spatial econometric context. This correction is used in the MATLAB code for this project, provided in Elhorst (2014). For the primary variable of interest, the direct effects results reported here are similar to those found in previous studies that do not take into account spatial dependence. They show either significant negative, or non-significant coefficients for the EFFRPS variable. However, once the indirect effects and total effects estimates are considered, the results change. 
In all specifications, except for Model 3, I find a positive significant total effect, which includes spillover effects, for the EFFRPS variable. The coefficients range from 0.8 in Model 1 to 1.6 in Model 2, indicating that a 1 percentage point increase in the RPS targets within a region will increase each the region's share of renewable generation by between 0.8 and 1.6 percentage points on average. 
Table 4: Spatial Durbin model regression results

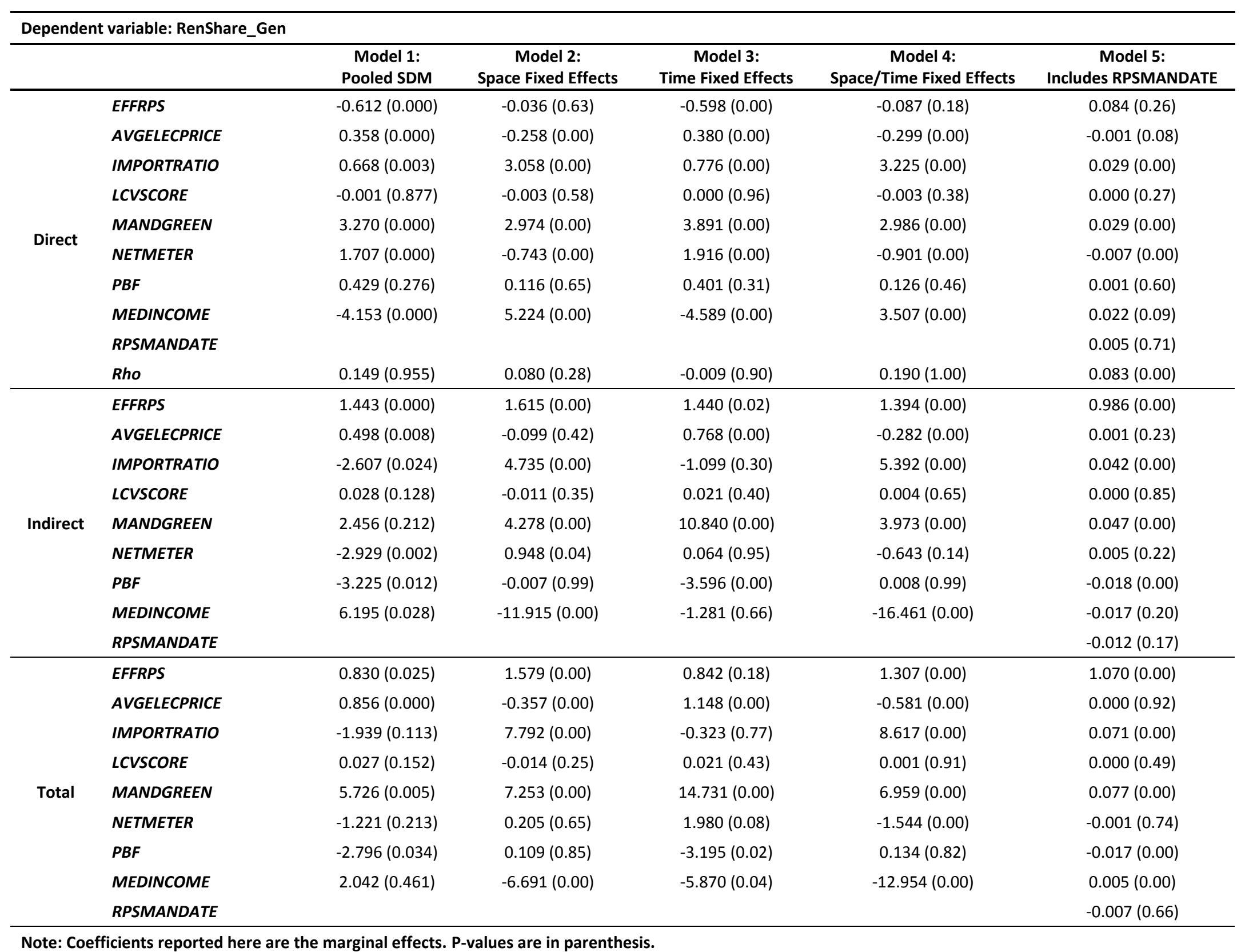


In none of the specifications do I find significance in the $\rho$ parameter, indicating a lack of significance in the spatially lagged dependent variable. This result does not mean that there is no spatial dependence at all, however, as the $\theta$ parameters on the spatially weighted $\mathrm{X}$ variables are significant in most cases, as are the indirect effects estimates, including for the EFFRPS variable. As mentioned above, the lack of significance in the $\rho$ variable indicates that the SDM model in this case will be functionally equivalent to an SLX model that takes into account spatial dependence only in the $\mathrm{X}$ variables. If the $\rho$ parameter were significant, it would mean that some of the gains in renewable generation were due to increases in renewable generation in neighboring states, which would suggest a clustering effect of renewable generation. However, the lack of significance on the $\rho$ variable indicates that the effects on renewable generation are felt primarily through the spatial interaction of nearby states' RPS laws and not through clustering.

Effects estimates of the other control variables are also given in Table 4 . The coefficient on electricity prices (AVGELECPRICE) is generally negative, but small, with less than 1 percent additional renewable generation for each cent per $\mathrm{kWh}$. The coefficients on IMPORTRATIO are generally positive, or not significant. These results show that a 1 percent increase in the percentage of imported generation will increase renewable generation by approximately 8.6 percent, indicating that states that import electricity have a higher renewable share than those that export it. This may indicate that those states that export electricity are more likely to produce energy using fossil fuels than renewables. This study finds that a state's LCV Score has little effect on the renewable share in that state. The total effects estimates for LCVSCORE were not significant in all four models shown. The other renewable policy variables had mixed impacts. Mandatory green power laws (MANDGREEN) had a positive association with a state's 
renewable share, while net metering (NETMETER) and public benefit funds $(P B F)$ were largely not significant. Median Income (MEDINCOME) had a positive direct impact on a state's renewable share, but a negative impact overall. This might indicate that more renewables are prevalent in states with higher incomes, but that these states import power from lower-income states with more fossil fuel generation, which is consistent with the net-import results. Model 5 incorporates a dummy variable that equals 1 if a state has a mandatory RPS policy and zero if a state has a non-mandatory goal (RPSMANDATE). Inclusion of this variable had little effect on the results, and RPSMANDATE itself was not significant.

My spatial weight matrix is somewhat unusual, in that it does not follow typical governmental boundaries. In order to check the robustness of my results, I specified several alternate spatial weight matrices. ${ }^{4}$ For example, in one model I recalculated the variables using a weight matrix whose neighbor relationships are weighted by the share of capacity of that state in the NERC region. This weight matrix takes into account the strength of the neighbor relationship in terms of the capacity shared by each state. Other specifications include a model using average capacity weights; and two that defined neighbor relationships as those meeting a minimum level of capacity share. In general, I find that the results presented above are somewhat sensitive to the specification of the spatial weight matrix. In the capacity-weighted model, for example, the results for my primary variable of interest become non-significant with this weight matrix specification. However, if I remove the time fixed effects, the significance returns. The results from the threshold models indicate that the significance of the primary variable falls as the threshold rises.

\footnotetext{
${ }^{4}$ Regression results for these models are available in the chapter appendix.
} 
Despite the varying results using different weight matrices, I believe my original specification is sound for a variety of reasons. First, I believe that the lack of significance in the capacity-weighted model can at least partially be explained by interaction between the weight matrix and the time fixed effects in the model. Spatial weight matrices generally are timeinvariant, because the spatial relationships do not change over time. In the capacity-weighted model, however, the weight matrix changes every year, and thus may be more highly correlated with the time fixed effects. Second, the threshold models eliminate contiguity for states that share a fairly significant portion of their capacity. This places a restriction on whether states can influence one another, which I believe is unwarranted. More broadly, I feel that specifying a weight matrix weighted by capacity is troublesome econometrically. Weight matrices are assumed to be independent of the variables in the regression. By specifying a neighbor relationship weighted by capacity, I have introduced the potential for endogeneity between the weight matrix and both the dependent variable and my primary independent variable, which are both functions of existing capacity. For all of these reasons, I feel a more traditional notion of contiguity is preferred in this study.

\section{Conclusions}

As the results in Table 4 show, the majority of the spatial Durbin specifications provide similar interpretations for my primary variable of interest. The direct effects estimates for all four models are either negative or not significantly different from zero, which coincides with evidence found in the previous literature. However, with the exception of Model 3, the indirect results show positive and significant effects in most specifications, yielding positive and significant total effects. I prefer the results from Model 4 as a measure of the total effect of these policies. In this model I have controlled for both the spatial and time-period specific effects, 
which helps separate the effects of the RPS policy from other state-specific and time-specific conditions that I cannot account for. The total effects estimate is the lowest of all of the fixed effects models, indicating that a 1 percentage point increase in the effective RPS of a region would produce a 1.3 percentage point increase in renewable generation share in the region on average. This represents an elasticity at the means of 0.1 , which makes intuitive sense, given that most states with RPS laws have other policies in place to incentivize renewable generation beyond their RPS policies, and thus RPS laws may not be entirely responsible for increasing renewable generation.

These results, taken as a whole, indicate that previous studies of RPS laws that do not account for spatial dependence among states are missing important information to judge the effectiveness of these policies. I find evidence that while stronger RPS laws do not necessarily increase the share of renewable energy within a state, they do have a positive impact on the NERC region generally. For example, California's relatively strong RPS is likely causing new wind capacity to be built in Wyoming and Idaho, which do not have strong RPS laws. This conclusion is bolstered by the lack of significance in the coefficient for the $\rho$ variables, which indicates that increases in renewable generation are not being driven primarily by clustering effects but instead by the RPS laws themselves. This leads me to believe that spatial dependence is a primary reason why previous literature has shown little effect on own-state renewable generation from RPS laws.

Promotion of renewable energy has typically been cited as a primary reason that RPS laws have been passed in states. However, policy makers have also promoted the laws as potential engines of economic development (see Lyon and Yin 2010), often predicting that strong RPS laws will promote new renewable capacity construction and local employment. My 
findings show that RPS laws may be more successful at the former than the latter. Though RPS policies do not necessarily promote renewable generation within a given state, these policies do appear to be effective in stimulating renewable generation on a system-wide basis. This is an important finding because it indicates that electricity markets, which are not bound by state political borders, are incorporating renewables into the fuel mix by finding the least-cost locations for renewable capacity to serve load in states with stronger RPS laws. 


\section{Chapter 1 Appendix}

This appendix describes in detail the data used in this chapter and the sources for the data. Also I describe six alternate weight matrix specifications described above used to test the robustness of my results.

\section{Data Description}

Most of the data this chapter is publicly available from the US Energy Information Administration (EIA). I also draw from the Database of State Incentives for Renewables and Efficiency, the League of Conservation Voters, and the US Census Bureau. The dataset contains an observation for each of the lower 48 US states (excluding Hawaii and Alaska), and 23 years from 1990 to 2012, yielding a balanced panel of 1,104 observations. 
Table 5: Data description and sources

\begin{tabular}{|c|c|c|}
\hline Variable & Description & Source \\
\hline RENSHARE_GEN & Share of renewable generation in each state. & $\begin{array}{l}\text { EIA forms EIA-923 (and } \\
\text { predecessor forms } 906 \text { and } \\
920 \text { ); EIA-867 }\end{array}$ \\
\hline EFFRPS & $\begin{array}{l}\text { Effective Renewable Portfolio Standard. Author calculated } \\
\text { variable indicating the additional renewable generation } \\
\text { required beyond the existing generation. }\end{array}$ & $\begin{array}{l}\text { EIA forms EIA-923 (and } \\
\text { predecessor forms } 906 \text { and } \\
\text { 920); EIA-867; EIA-861; EIA } \\
\text { Detailed State Data; Database of } \\
\text { State Incentives for Renewables } \\
\text { and Efficiency }\end{array}$ \\
\hline AVGELECPRICE & Mean residential electricity price. & EIA State Historical Tables \\
\hline IMPORTRATIO & $\begin{array}{l}\text { Ratio of a state's sales to its generation. Calculated as the } \\
\text { difference between sales and generation divided by sales. }\end{array}$ & EIA Detailed State Data \\
\hline LCVSCORE & $\begin{array}{l}\text { The average of scores on the annual League of } \\
\text { Conservation Voters Scorecard for congressional } \\
\text { representatives and senators for each state and year. }\end{array}$ & $\begin{array}{l}\text { League of Conservation Voters } \\
\text { Scorecard }\end{array}$ \\
\hline MANDGREEN & $\begin{array}{l}\text { An indicator variable for whether a state has a policy } \\
\text { requiring utilities to offer customers the option to } \\
\text { purchase renewable energy. }\end{array}$ & $\begin{array}{l}\text { Database of State Incentives for } \\
\text { Renewables and Efficiency }\end{array}$ \\
\hline NETMETER & $\begin{array}{l}\text { An indicator variable for whether a state has a net } \\
\text { metering policy. }\end{array}$ & $\begin{array}{l}\text { Database of State Incentives for } \\
\text { Renewables and Efficiency }\end{array}$ \\
\hline PBF & $\begin{array}{l}\text { An indicator variable identifying the presence of a public } \\
\text { benefit fund for renewable energy in a particular state. }\end{array}$ & $\begin{array}{l}\text { Database of State Incentives for } \\
\text { Renewables and Efficiency }\end{array}$ \\
\hline MEDINCOME & Median Household Income for each state by year. & US Census Bureau \\
\hline
\end{tabular}

\section{Alternate weight matrices}

The results from my alternate weight matrix specifications are detailed in Table 6. Model 1 recalculates the models using a weight matrix whose neighbor relationships are weighted by the share of capacity of that state in the NERC region. In other words, if a state has 10 percent of its capacity in the WECC region and another has 100 percent of its capacity in the same region, then the neighbor relationship between in the weight matrix would be 0.1 . As the table indicates, the results for my primary variable of interest become non-significant with this weight matrix specification. However, if I remove the time fixed effects (Model 2), the significance returns. Specification of a random effect model (Model 3), also finds significant results, but these are somewhat questionable as a Hausman test between this model and Model 1 indicates a strong 
significant preference for the fixed effect model. I also specified a model using average capacity weights that were split into three time periods corresponding with NERC region boundary changes in 1997 and 2006. In this specification the results for EFFRPS are still not significant. The last two model specification use weight matrices that are based on simple contiguity. However, neighbor relationships that did not meet a minimum level of capacity share were eliminated from the weight matrix. In Model 5, this threshold was 5 percent, meaning that if a less than 5 percent of a state's capacity was in a particular NERC region, that NERC region was eliminated from the matrix. Model 6 is similar, except that the threshold is set at 10 percent. 
Table 6: Alternate weight matrix specification results

\begin{tabular}{|c|c|c|c|c|c|c|c|}
\hline \multicolumn{8}{|c|}{ Dependent variable: RenShare_Gen } \\
\hline & & $\begin{array}{c}\text { Model 1: } \\
\text { Capacity Weighted } \\
\text { Space/Time Fixed Effects } \\
\end{array}$ & $\begin{array}{c}\text { Model 2: } \\
\text { Capacity Weighted } \\
\text { Space Fixed Effect } \\
\end{array}$ & $\begin{array}{c}\text { Model 3: Capacity } \\
\text { Weighted Random } \\
\text { Effect }\end{array}$ & $\begin{array}{c}\text { Model 4: } \\
\text { Mean Capacity } \\
\text { Weighted }\end{array}$ & $\begin{array}{c}\text { Model 5: } \\
\text { 5\% Threshold }\end{array}$ & $\begin{array}{l}\text { Model 6: } \\
\text { 10\% Threshold }\end{array}$ \\
\hline \multirow{9}{*}{ Direct } & EFFRPS & $-0.028(0.699)$ & $0.123(0.105)$ & $0.154(0.030)$ & $-0.028(0.690)$ & $-0.049(0.442)$ & $-0.057(0.445)$ \\
\hline & AVGELECPRICE & $-0.160(0.067)$ & $-0.018(0.818)$ & $0.003(0.973)$ & $-0.161(0.056)$ & $-0.275(0.000)$ & $-0.219(0.006)$ \\
\hline & IMPORTRATIO & $3.527(0.000)$ & $3.628(0.000)$ & $3.142(0.000)$ & $3.545(0.000)$ & $3.029(0.000)$ & $3.396(0.000)$ \\
\hline & LCVSCORE & $-0.002(0.776)$ & $-0.001(0.809)$ & $0.002(0.713)$ & $-0.001(0.914)$ & $-0.002(0.566)$ & $0.001(0.904)$ \\
\hline & MANDGREEN & $2.910(0.000)$ & $3.015(0.000)$ & $2.858(0.000)$ & $2.928(0.000)$ & $2.870(0.000)$ & $3.220(0.000)$ \\
\hline & NETMETER & $-0.918(0.000)$ & $-0.751(0.000)$ & $-0.673(0.001)$ & $-0.885(0.000)$ & $-0.958(0.000)$ & $-0.872(0.000)$ \\
\hline & PBF & $0.461(0.064)$ & $0.180(0.461)$ & $0.024(0.922)$ & $0.451(0.058)$ & $0.173(0.319)$ & $0.443(0.075)$ \\
\hline & MEDINCOME & $2.317(0.121)$ & $2.687(0.057)$ & $3.721(0.005)$ & $2.313(0.149)$ & $1.094(0.000)$ & $2.272(0.116)$ \\
\hline & RHO & $0.187(1.000)$ & $0.097(0.246)$ & $0.103(0.000)$ & $0.205(1.000)$ & $0.164(1.000)$ & $0.190(1.000)$ \\
\hline \multirow{8}{*}{ Indirect } & EFFRPS & $-0.086(0.721)$ & $0.765(0.000)$ & $0.938(0.000)$ & $-0.100(0.669)$ & $0.681(0.000)$ & $-0.648(0.030)$ \\
\hline & AVGELECPRICE & $-0.380(0.026)$ & $0.202(0.080)$ & $0.171(0.132)$ & $-0.382(0.023)$ & $-0.400(0.000)$ & $-0.296(0.069)$ \\
\hline & IMPORTRATIO & $7.210(0.000)$ & $8.448(0.000)$ & $7.224(0.000)$ & $7.234(0.000)$ & $3.097(0.000)$ & $5.028(0.000)$ \\
\hline & LCVSCORE & $-0.055(0.001)$ & $-0.055(0.000)$ & $-0.044(0.000)$ & $-0.052(0.001)$ & $-0.016(0.036)$ & $-0.040(0.007)$ \\
\hline & MANDGREEN & $2.666(0.014)$ & $3.940(0.000)$ & $3.254(0.000)$ & $2.306(0.023)$ & $5.643(0.000)$ & $4.058(0.001)$ \\
\hline & NETMETER & $-1.277(0.011)$ & $-0.218(0.564)$ & $-0.391(0.294)$ & $-1.373(0.010)$ & $-1.272(0.000)$ & $-2.031(0.000)$ \\
\hline & PBF & $1.632(0.011)$ & $-0.136(0.798)$ & $-0.926(0.055)$ & $1.572(0.012)$ & $1.243(0.007)$ & $1.631(0.010)$ \\
\hline & MEDINCOME & $-3.002(0.302)$ & $-8.533(0.000)$ & $-3.125(0.020)$ & $-3.013(0.312)$ & $0.635(0.000)$ & $0.880(0.043)$ \\
\hline \multirow{8}{*}{ Total } & EFFRPS & $-0.114(0.660)$ & $0.888(0.000)$ & $1.092(0.000)$ & $-0.128(0.608)$ & $0.632(0.000)$ & $-0.705(0.029)$ \\
\hline & AVGELECPRICE & $-0.541(0.004)$ & $0.184(0.063)$ & $0.174(0.079)$ & $-0.543(0.003)$ & $-0.675(0.000)$ & $-0.515(0.004)$ \\
\hline & IMPORTRATIO & $10.738(0.000)$ & $12.076(0.000)$ & $10.366(0.000)$ & $10.779(0.000)$ & $6.126(0.000)$ & $8.424(0.000)$ \\
\hline & LCVSCORE & $-0.057(0.002)$ & $-0.057(0.000)$ & $-0.042(0.000)$ & $-0.053(0.003)$ & $-0.018(0.023)$ & $-0.040(0.018)$ \\
\hline & MANDGREEN & $5.576(0.000)$ & $6.955(0.000)$ & $6.113(0.000)$ & $5.234(0.000)$ & $8.513(0.000)$ & $7.279(0.000)$ \\
\hline & NETMETER & $-2.195(0.000)$ & $-0.969(0.011)$ & $-1.064(0.005)$ & $-2.258(0.000)$ & $-2.230(0.000)$ & $-2.903(0.000)$ \\
\hline & PBF & $2.093(0.003)$ & $0.044(0.936)$ & $-0.901(0.056)$ & $2.023(0.003)$ & $1.416(0.004)$ & $2.074(0.002)$ \\
\hline & MEDINCOME & $-0.685(0.840)$ & $-5.846(0.001)$ & $0.596(0.000)$ & $-0.700(0.841)$ & $1.729(0.000)$ & $3.152(0.082)$ \\
\hline
\end{tabular}




\title{
Chapter 2: Short-run effects of regional renewable penetration on the fossil fuel mix in electricity generation
}

\begin{abstract}
A number of studies have attempted to ascertain the effect of incentives promoting renewable power generation on fossil fuel utilization. A number of economic or theoretical models have predicted that strict renewables laws will cause a replacement of natural gas generation in the market with renewable generation. However, a number of industry analysts have described the importance of natural gas as a backup fuel for intermittent renewable generation. This would suggest a complementarity between the two types of fuels, which would indicate that as renewables represent a rising share of power generation, natural gas should also increase. I find no evidence that renewable generation is complementary to natural gas generation in terms of encouraging greater output from existing plants. My results show no significant effects of renewable penetration on capacity factors of natural gas combined cycle plants, and I find that it is associated with significantly reduced capacity factors for natural gas combustion turbines. I also find that as renewables become a larger share of power generation, generating units powered by coal are used more intensively.
\end{abstract}

\section{Introduction}

As public policies promoting renewable energy, such as renewable portfolio standards (RPS) and net metering, have proliferated in states across the United States, several studies have attempted to ascertain whether they have been effective at increasing renewable energy generation in the states that adopt the policies. The findings of these studies has been mixed, but there is little doubt that renewables are becoming a larger share of the nation's energy mix. Since 2001, the share of electricity generation produced by renewable sources has nearly tripled, rising from 3.2 percent in 2001 to almost 7 percent in 2014 (EIA 2014b).

This chapter leaves aside the question of whether the particular policies promoting renewables have been effective and instead concentrates the effects of increased renewable penetration on the fuel mix in power generation. I attempt to bridge two lines of literature that have seemingly contradictory findings. A number of economic or theoretical models (for example, Fischer and Preonas 2010, Bird et al. 2011, Palmer and Burtraw 2005), have predicted 
that strict renewables laws will cause a replacement of natural gas generation in the market with renewable generation. However, a number of industry analysts (including Lauby, Moura, and Rollison 2011, Puga 2010, Shuai et al. 2010) described the importance of natural gas as a backup fuel for intermittent renewable generation. This would suggest a complementarity between the two types of fuels, which would indicate that as renewables represent a rising share of power generation, natural gas should also increase.

I seek to evaluate these largely theoretical assessments by applying econometric techniques to plant- and unit-level generation and cost data to measure the effect of increased penetration of renewables on dispatch rates of individual generating units. My results give conflicting evidence about which of these literatures is correct. I find no evidence that renewable generation is complementary to natural gas generation in terms of encouraging greater output from existing plants. My results show no significant effects of renewable penetration on capacity factors of natural gas combined cycle plants; and I find that renewables are associated with significantly reduced capacity factors for natural gas combustion turbines. I also find that as renewables become a larger share of power generation, generating units powered by coal are used more intensively.

I interpret these results to mean that as renewables have entered the market, the intermittent and variable nature of these technologies has increase the value and demand for load-following services. This increased demand for load-following has been met largely by natural gas combined cycle (NGCC) plants because of their ability to ramp up and down quickly, and their low marginal costs of generation. In turn the increased share of generation from NGCC has crowded out generation from natural gas combustion turbines, thus reducing their capacity 
factors, while simultaneously increasing the base load share of coal-fired power plants, which pushed up capacity factors for these plants.

\section{Background and literature review}

The impact of renewable policies on the fuel mix has primarily been studied using econometric simulations. Palmer and Burtraw (2005) model RPS policies with varying degrees of stringency, ranging from a 5\% nominal standard to a $20 \%$ nominal standard. Most relevant for the current study, the authors examine the effect of RPS standards on different fuel types and find that low RPS standards will have little effect on reducing fossil fuels, but at higher levels, they will replace not only coal and natural gas, but also nuclear energy. Fischer and Newell (2008), and an extension in Fischer and Preonas (2010), examined six types of energy policies using a theoretical model and simulation. Their model predicted that RPS policies will increase renewable electricity generation and that generation from gas will fall more quickly than generation from coal. Bird et al (2011) used a simulation model to examine the effects of combining cap-and-trade policies with RPS, finding that strict RPS laws alone sharply reduce the amount of generation from natural gas. Natural gas remains a larger share of generation when an RPS is combined with cap-and-trade because of the fuel's lower carbon density.

Econometric simulation model predictions that renewables will largely replace natural gas appear to contradict much of the industry literature surrounding implementation of largescale renewable energy on the electric grid. This discrepancy may arise from the simulation models' incomplete treatment of renewables' intermittency of generation. Puga (2010), for example, exemplifies much of the prevailing view that variability in the output from renewable energy requires a backstop technology that can ramp up quickly as renewables ramp down. Puga wrote that wind generation was already displacing higher-cost coal and some natural gas 
generation, causing increased cycling costs at coal-fired power plants. Researchers at NERC (Lauby, Moura, and Rollison 2011) recognized the importance of new practices to accommodate greater levels of renewable energy on the electric grid. The authors wrote that as renewables become a larger portion of generation on the grid, system operators will be required to better accommodate the unpredictability of generation. Hittinger, Whitacre, and Apt (2010) also recognized the importance of natural gas in the fuel mix as renewables increase. The authors devised a model for smoothing the variability of wind generation using both natural gas generation and battery storage. Lastly, Shuai et al (2010) proposed that system operators better incorporate ramp-rates into their dispatch decisions as renewables add uncertainty to the generation mix.

\section{Methodology}

Because of these conflicting findings in the economics and industry literature, this paper examines the effects of renewable penetration empirically to determine what effects this rise in renewable generation has had over time. In theory, renewable incentives work to increase the capacity of renewable generation, but the question of how renewable energy is incorporated into the electricity market becomes an important question as the share of renewable energy increases. Theoretically in a competitive generation market, the decision to dispatch a plant is based on the offer price of the generator, which is primarily determined by the marginal cost of production of that generation, the majority of which for most generators are fuel costs (Stoft 2002). In a competitive market environment, generators cover their capital costs from the inframarginal rents between the wholesale price and the marginal cost offer price. Demand spikes that drive up the average wholesale price thus pay for capital investments. Since renewable generators generally 
have zero (or in the presence of subsidies, negative) fuel cost, the entire output from wind farms and solar arrays is dispatched to the grid when they are operating.

In reality, however, the dispatch decision is not just related to marginal cost. The ability of a plant to ramp up quickly in the case of a demand spike is also a factor. Stoft (2008) suggested that renewable generation is best considered as negative load. Under this formulation when renewable energy ramps down, the rest of the system experiences a demand spike. To deal with this demand increase, the wholesale price must increase, which brings the next lowest marginal cost plant into the generation mix. As is shown in Table 7, coal-fired power plants, which are primarily used for base load power, have a low marginal cost of generation but also low rampability. Because of these factors, coal plants are not typically used for load following and run at high capacity factors. Natural gas combined cycle plants have a somewhat higher marginal cost of generation, but can also be ramped up much more quickly. Finally, natural gas combustion turbines have a very high marginal cost, but can be ramped up very quickly in response to increases in load. For these reasons, natural gas plants combined cycle plants tend to be used more for load following, and natural gas turbines are mostly used for peak load times when the wholesale prices are high.

Renewables cannot be dispatched and they generate power intermittently. Thus capacity factors for renewables are dependent on factors outside the control of the utility, which means they cannot be used for base load power. However, because of their near-zero marginal cost, they will displace other types of generation when in operation. Therefore, if renewables and natural gas are substitutes, renewables should most significantly affect those generators in the middle range of capacity factors, or "shoulder" plants, which tend to be older coal-fired plants and NGCCs in most traditional systems. However, to the extent that renewable production is 
uncorrelated with demand, the intermittent nature of renewable energy should tend to increase wholesale price volatility, and thus increase the capacity factors of peaking plants, which include gas-fired combustion turbines.

Table 7: Ramp rates and variable costs by generating technology

\begin{tabular}{|c|c|c|c|c|}
\hline & & $\begin{array}{c}\text { Natural Gas } \\
\text { Combined Cycle }\end{array}$ & $\begin{array}{c}\text { Natural Gas } \\
\text { Combustion } \\
\text { Turbine } \\
\end{array}$ & Coal \\
\hline \multirow{2}{*}{$\begin{array}{l}\text { Ramp } \\
\text { Rates }\end{array}$} & Spin Ramp Rate (\%/min)* & 5.0 & 8.3 & 2.0 \\
\hline & Quick Start Ramp Rate (\%/min)* & 2.5 & 22.2 & $\mathrm{n} / \mathrm{a}$ \\
\hline \multirow{3}{*}{$\begin{array}{l}\text { Variable } \\
\text { Costs }\end{array}$} & Variable O\&M Costs (\$/MWh)* & 3.7 & 29.9 & 3.7 \\
\hline & Fuel Costs (\$/MWh)† & 34.0 & 52.7 & 21.3 \\
\hline & Total Variable Cost (\$/MWh) & 37.7 & 82.6 & 25.0 \\
\hline
\end{tabular}

In order to test the impact of renewable penetration on the fuel mix, I derive a panel model that regresses the capacity factor of individual generators on the renewable penetration in each generator's NERC region. My hypothesis is that an increased share of renewables in a given location will drive up the capacity factors for natural gas fired combustion turbines, given that they better complement intermittent renewable power than large coal or nuclear plants. As renewable penetration increases, I hypothesize that capacity factors for natural-gas-fired plants will also increase relative to other plants. My model is as follows:

$$
\text { CAPFAC }_{i t}=\alpha_{1} R E N S H A R E_{i t}+\alpha_{2} \text { FUELCOSTt }+X_{i t} \beta+\Delta_{i t} \gamma_{2}+\epsilon_{i t}
$$

Equation (7) tests the effects on fossil fuel plants of an increase of renewables in the fuel mix. I regress the annual capacity factor of each prime mover $(C A P F A C)$ on the renewable share (RENSHARE) in the prime mover's NERC region, and the fuel cost associated with that prime mover's fuel. For this equation the RENSHARE variable is defined as the share of renewable 
generation within each region of the North American Electric Reliability Corporation (NERC). Also of primary interest is the rampability of each technology. According to Macmillan, Antonyuk, and Schwind (2013), rampability is largely a function of the technology and the age of the plant. To account for this factor I incorporate the mean age for each PMU (PMUAGE), taking into account the installation date of all generating units of the same primary fuel and prime mover technology.

I control for the price of each plant's primary fuel relative to the mean fuel cost for the plant's alternative fuel (RELFUELCOST). In the case of coal plants, for example, RELFUELCOST is the price per MWh for each PMU relative to the mean price of natural gas generation in that year; the variable is reversed for natural gas plants. I calculate the mean price for natural gas and coal using data from the EIA Monthly Energy Review (2014c). As the fuel cost variables incorporate the heat rate of the given PMU, they are controlling for the efficiency of the PMU relative to the average efficiency of each type of generation as well as the price of fuel faced by that PMU. The fuel cost variable is calculated from EIA-923 (EIA 2013b) and FERC Form 423 (EIA 2011) for historical data. Due to data restrictions, the fuel cost was unavailable for some plants in some years. In these cases, I calculate the average heat rate for the type of fuel and prime mover technology and assign that heat rate to plants of similar age. I would expect that as the price of a plant's fuel rises relative to competing fuels, the plant's capacity factor will fall, though the elasticities of various fuels will vary significantly from one another. To measure environmental sentiment, which may affect the demand for renewable generation, I use the average score on the League of Conservation Voters Scorecard (LCV 2013), which is a measure of how the votes of each member of the US Congress coincide with the interests of the LCV. I take the mean of the scores for each state's legislators to derive the 
average state score (LCVSCORE). I also control for electricity demand using cooling degree days (COOLDEGDAYS). This data from the National Weather Service (2014) measures the number of days and degrees the temperature in a state is above 65 degrees. Lastly, in some specifications, I include fixed effects for the prime mover unit, year, state, or NERC region.

\section{Multi-level model specification}

In addition to traditional panel data models, I also estimate a multi-level (hierarchical) model for these data. Popularized in the educational statistics literature, multi-level models allow an analysis of grouped data by nesting variables within larger groups. In this study, specifying a multi-level model allows me to independently assess the group effect of a NERC region on the plants located within that region. In practice, multi-level models are estimated using mixed models of both fixed and random effects, and allow for estimates of random intercepts and random slopes for each NERC region. Following 2008), I specify a model of the following form:

$$
Y_{i t}=X_{i t} \beta+Z_{i t} \delta_{i}+\varepsilon_{i t}
$$

where $Z_{i t}$ is a matrix of random effects for the intercept and slope of my primary independent variable NERCRENSHARE grouped within each NERC region, and $\delta_{i}$ is a set of coefficients for the random effects in each NERC region.

\section{Data}

The data used in the estimation is a panel of power plant variables for the years 19902013 disaggregated by plant, fuel and prime mover. The capacity data is drawn from Energy Information Administration EIA-860 (EIA 2013a) and is joined with generation data from EIA906/923 (EIA 2013b). The capacity data is reported for each generating unit within a plant, and contains both the fuel used and the unit's prime mover technology. The reported generation data, however, is aggregated by fuel and prime mover types within the plant, and thus each 
observation may include multiple generating units that use the same fuel and prime mover technology. Because of this difference, I have adopted the term "prime mover unit" (PMU) to refer to the units of analysis in this study. As discussed below, the reporting difference between the capacity survey and generation survey caused some problems matching the capacity data with the generation data to calculate the capacity factors. Though the data-matching problems could have been somewhat alleviated had I aggregated the data for each plant, I chose to keep the data disaggregated by prime mover and fuel in order to examine within-plant fuel switching between less rampable technologies to those with higher ramp rates technologies. An analysis on the plant level would not provide the necessary detail if there were multiple units using different technologies at a particular plant.

Capacity factors for each PMU are calculated in the typical way, by dividing the generation in MWh from a particular unit by its potential generation:

$$
\text { CAPFAC }_{i}=\frac{\text { Generation }_{i}}{\text { Capacity }_{i} \times 8760}
$$

where 8760 is the number of hours in a year. As mentioned above, EIA generation data is not available on a generating unit basis for non-steam power generation, thus matching plant-prime mover pairs in the generation files with corresponding pairs in the capacity files is difficult in a small percentage of cases where generating units have overlapping secondary fuel sources. In these cases, I assign each megawatt-hour of generation to a particular PMU according to its probability of having come from that generating unit. This probability is derived from Bayes Rule using the following formula:

$$
P\left(P M U_{i} \mid F_{j}\right)=\frac{P\left(F_{j} \mid P M U_{i}\right) \cdot P\left(P M U_{i}\right)}{P\left(F_{j}\right)}=\frac{S F P_{i} \cdot C S_{P M U_{i}}}{S F P_{i} \cdot C S_{P M U_{i}}+\left(1-S F P_{-i}\right) \cdot C S_{P M U_{-i}}}
$$


Under this formulation, the probability that a particular megawatt-hour of generation came from $P M U_{i}$ given fuel $j\left(F_{j}\right)$ is proportional to the conditional probability of $F_{j}$ given $P M U_{i}$ times the prior probability of $P M U_{i}$. For any secondary fuel, the conditional probability of a secondary fuel's usage is calculated as the average share of generation that comes from nonprimary fuels, what I have called the secondary fuel percentage $(S F P)$. It is calculated from those plants in the dataset for which full information is available. The prior probability is the share of each plant's capacity $(C S)$ represented by that prime mover unit. Thus the joint probability is the SFP multiplied by that prime mover unit's share of capacity. The normalizing constant is the sum of each of the joint probabilities of the current PMU and any other PMUs within each plant. This point probability yields a weight for each fuel type and PMU that is then multiplied by the total generation of that fuel type to assign part of that generation to a particular PMU.

The final dataset is an unbalanced panel of capacity factors and control variables disaggregated by PMU. The data is unbalanced because many of the plants are not in operation, or may be missing from the dataset, in a given year. Some units exit the market or shut down operations temporarily and thus drop out of the dataset. Also, new plants have come online in the 23 years of data available. Table 8 details the summary statistics for this dataset. 
Table 8: Summary statistics

\begin{tabular}{|c|c|c|c|c|c|c|c|}
\hline $\begin{array}{l}\text { Prime Mover } \\
\text { Technology }\end{array}$ & Variable & $\begin{array}{c}\text { Number of } \\
\text { Observations }\end{array}$ & Mean & $\begin{array}{l}\text { Standard } \\
\text { Deviation }\end{array}$ & Median & Minimum & Maximum \\
\hline \multirow{6}{*}{$\begin{array}{l}\text { Coal } \\
\text { Steam Boiler }\end{array}$} & CAPFAC & 7,883 & 52.67 & 22.76 & 57.29 & 0 & 99.97 \\
\hline & NERCRENSHARE & 7,883 & 0.01 & 0.02 & 0 & 0 & 0.17 \\
\hline & RELFUELCOST & 7,883 & 0.47 & 0.36 & 0.4 & 0 & 3.84 \\
\hline & PMUAGE & 7,883 & 30.62 & 12.77 & 30.69 & 0 & 82 \\
\hline & COOLDEGDAYS & 7,883 & 1,098 & 718 & 878 & 38 & 3,799 \\
\hline & LCVSCORE & 7,883 & 43.89 & 19.21 & 41.3 & 0 & 98.33 \\
\hline \multirow{6}{*}{$\begin{array}{l}\text { Natural Gas } \\
\text { Combined Cycle }\end{array}$} & CAPFAC & 3,217 & 34.91 & 25.82 & 32.43 & 0 & 99.83 \\
\hline & NERCRENSHARE & 3,217 & 0.03 & 0.02 & 0.03 & 0 & 0.17 \\
\hline & RELFUELCOST & 3,217 & 2.91 & 1.86 & 2.5 & 0 & 17.45 \\
\hline & PMUAGE & 3,217 & 11.76 & 9.14 & 10 & 0 & 60.93 \\
\hline & COOLDEGDAYS & 3,217 & 1,543 & 1,010 & 1,077 & 94 & 3,799 \\
\hline & LCVSCORE & 3,217 & 50.16 & 23.06 & 48 & 2.5 & 100 \\
\hline \multirow{6}{*}{$\begin{array}{l}\text { Natural Gas } \\
\text { Combustion Turbine }\end{array}$} & CAPFAC & 11,187 & 13.36 & 25.23 & 1.62 & 0 & 99.88 \\
\hline & NERCRENSHARE & 11,187 & 0.03 & 0.03 & 0.02 & 0 & 0.17 \\
\hline & RELFUELCOST & 11,187 & 6.01 & 7.75 & 4.33 & 0 & 92.53 \\
\hline & PMUAGE & 11,187 & 17.83 & 12.12 & 16.03 & 0 & 59 \\
\hline & COOLDEGDAYS & 11,187 & 1,329 & 844 & 1,026 & 38 & 3,799 \\
\hline & LCVSCORE & 11,187 & 46.63 & 20.24 & 46.9 & 0 & 100 \\
\hline
\end{tabular}




\section{Results}

Table 9 shows the results for my estimates of equation (7). The first column reports the results for a pooled OLS model. The next three models incorporate varying fixed effects within a panel model context. And model 5 estimates a multi-level model with a random intercept and slope coefficient for the NERCRENSHARE variable. 
Table 9: Regression estimates

\begin{tabular}{|c|c|c|c|c|c|c|}
\hline \multicolumn{7}{|c|}{ Dependent variable: CAPFAC } \\
\hline & & $\begin{array}{l}\text { Model 1: } \\
\text { OLS }\end{array}$ & $\begin{array}{c}\text { Model 2: } \\
\text { PMU Fixed Effects }\end{array}$ & $\begin{array}{c}\text { Model 3: } \\
\text { NERC Fixed Effects }\end{array}$ & $\begin{array}{c}\text { Model 4: } \\
\text { State/NERC } \\
\text { Fixed Effects }\end{array}$ & $\begin{array}{c}\text { Model 5: } \\
\text { NERC Multilevel }\end{array}$ \\
\hline \multirow{7}{*}{$\begin{array}{l}\text { Coal } \\
\text { Steam }\end{array}$} & NERCRENSHARE & $164.737(0.000)$ & $57.312(0.001)$ & $102.524(0.000)$ & $111.771(0.000)$ & $-17.411(0.774)$ \\
\hline & RELFUELCOST & $-24.967(0.000)$ & $-12.035(0.000)$ & $-24.747(0.000)$ & $-22.973(0.000)$ & $-24.791(0.000)$ \\
\hline & PMUAGE & $-0.534(0.000)$ & $-0.057(0.502)$ & $-0.533(0.000)$ & $-0.522(0.000)$ & $-0.540(0.000)$ \\
\hline & COOLDEGDAYS & $0.002(0.000)$ & $0.002(0.018)$ & $0.000(0.565)$ & $0.002(0.263)$ & $0.000(0.504)$ \\
\hline & LCVSCORE & $-0.019(0.121)$ & $0.009(0.467)$ & $-0.023(0.103)$ & $-0.027(0.214)$ & $-0.014(0.326)$ \\
\hline & NERCRENSHARE (RE) & & & & & $-8.678(0.554)$ \\
\hline & $A d j-R^{2}$ & 0.293 & 0.208 & 0.343 & 0.400 & \\
\hline \multirow{7}{*}{$\begin{array}{l}\text { Natural Gas } \\
\text { Combined } \\
\text { Cycle }\end{array}$} & NERCRENSHARE & $327.652(0.000)$ & $10.641(0.742)$ & $42.241(0.399)$ & $-6.761(0.893)$ & $-73.484(0.490)$ \\
\hline & RELFUELCOST & $-0.839(0.001)$ & $-0.337(0.097)$ & $-0.427(0.098)$ & $-0.282(0.267)$ & $-0.378(0.139)$ \\
\hline & PMUAGE & $-0.239(0.000)$ & $-0.431(0.004)$ & $-0.272(0.000)$ & $-0.358(0.000)$ & $-0.285(0.000)$ \\
\hline & COOLDEGDAYS & $0.005(0.000)$ & $0.010(0.000)$ & $0.003(0.000)$ & $0.010(0.001)$ & $0.003(0.000)$ \\
\hline & LCVSCORE & $0.059(0.022)$ & 0.105 (0.009) & $0.096(0.009)$ & $0.134(0.043)$ & $0.038(0.298)$ \\
\hline & NERCRENSHARE (RE) & & & & & $14.327(0.547)$ \\
\hline & $\operatorname{Adj-} R^{2}$ & 0.082 & 0.015 & 0.122 & 0.201 & \\
\hline \multirow{7}{*}{$\begin{array}{l}\text { Natural Gas } \\
\text { Combustion } \\
\text { Turbine }\end{array}$} & NERCRENSHARE & $68.537(0.000)$ & $-32.327(0.000)$ & $-54.002(0.000)$ & $-58.756(0.000)$ & $-142.424(0.050)$ \\
\hline & RELFUELCOST & $-0.239(0.000)$ & $-0.099(0.000)$ & $-0.169(0.000)$ & $-0.078(0.009)$ & $-0.168(0.000)$ \\
\hline & PMUAGE & $-0.159(0.000)$ & $-0.074(0.023)$ & $-0.125(0.000)$ & $-0.109(0.000)$ & $-0.127(0.000)$ \\
\hline & COOLDEGDAYS & $0.005(0.000)$ & $0.003(0.000)$ & $0.005(0.000)$ & $0.004(0.007)$ & $0.005(0.000)$ \\
\hline & LCVSCORE & $0.224(0.000)$ & $-0.002(0.825)$ & $0.197(0.000)$ & $0.035(0.177)$ & $0.180(0.000)$ \\
\hline & NERCRENSHARE (RE) & & & & & $4.296(0.521)$ \\
\hline & $A d j-R^{2}$ & 0.088 & 0.007 & 0.136 & 0.238 & \\
\hline
\end{tabular}


Examining the results for natural gas combined cycle plants first, I do not find a significant impact on capacity factors for NGCC plants from a change in the renewable share in a plant's NERC region. In the majority of the model specifications, the coefficient on my primary independent variable NERCRENSHARE is not significantly different from zero. The impact on a plant's capacity factor of the plant's fuel cost relative to coal also is not significantly different from zero in most model specifications. The largest impacts on NGCC capacity factors are felt from the age of the plant (PMUAGE), and the number of cooling degree days (COOLDEGDAYS). A one-year increase in the plant's age leads to a decrease in capacity factors of between 0.2 and 0.4 , an elasticity at the means of between -0.1 and -0.2 . Cooling degree days have a somewhat larger impact, with an elasticity of between 0.2 and 0.5 , indicating that a 10 percent increase in the number of cooling degree days results in an increase in the capacity of NGCC plants of between 2 and 5 percent. The impact on NGCC capacity factors from a state's LCVSCORE is not significantly different from zero in most models.

The share of renewable energy in the NERC region have a significant negative effect on capacity factors for natural gas combustion turbines. The results indicate that a 10 percentage point increase in renewable share results in a reduction in capacity factors for CT plants of between 0.03 and 0.14 - an elasticity of between -0.07 and -0.32 , depending on the specification. The impact of relative fuel cost is also negative, as expected, though relatively small in the case of combustion turbines. The largest impacts on CT capacity factors are felt from cooling degree days, where elasticities range from 0.27 to 0.51 , indicating that a 10 percent increase in the number of cooling degree days results in an increase in capacity factors of between 2.7 and 5.1 percent. This is as expected, given that the primary use of combustion turbines is in load following. Surprisingly, a state's $L C V S C O R E$ also played an outsized role in the capacity factor 
for combustion turbines. Excluding models where the coefficient for LCVSCORE was not significant, elasticities at the means for LCVSCORE ranged from 0.7 to 0.8 .

Examining the results for coal-fired plants, I find that except for the multi-level model, the coefficients for the NERCRENSHARE variable are similar across all models. The regressions results show a small statistically significant positive marginal effect of the NERC region's renewable share on the capacity factor for coal plants. An increase of 10 percentage points in the renewable share leads to a gain in coal plant capacity factors of between 0.06 and 0.16 - an elasticity at the means of between 0.01 and 0.03 - depending on the model specification. The coefficient is negative in the multi-level model for both the fixed effect and grouped random effect; however, the coefficient is not significantly different from zero in either case. By comparison, the results show that PMU's fuel cost relative to natural gas has a relatively high impact on capacity factors. The fuel cost relative to the coal plant capacity factor has an elasticity of approximately -0.2 in most models, meaning an increase in the relative fuel cost of 10 percent would result in a decrease in a plant's capacity factor of approximately 2 percent. The effect from the age of the plant $(P M U A G E)$ is similar, with an elasticity of -0.3 , indicating a 10 percent increase in the relative fuel cost would lead to a decrease in capacity factor of approximately 3 percent. The coefficients of COOLDEGDAYS and LCVSCORE are either not significantly different from zero, or small, with elasticities of less than 0.06 and greater than -0.03 respectively.

\section{Discussion}

Overall there is little evidence in my results to indicate a complementary relationship between natural gas combined cycle plants and renewable penetration, at least in the short run. Few of the models I estimate show significant results, and the OLS model that does show a 
positive significant association is not my preferred model. This result runs contrary to my expectation, and those of authors who emphasize the complementarity between renewables and NGCC, that natural gas plants are being used preferentially to back up renewables due to their ability to ramp up more quickly than coal plants when renewables ramp down. I do find strong evidence that natural gas combustion turbines are substitutes for renewables. In all of the models I estimated, gas turbine capacity factors were negatively associated with renewable penetration. My results for coal-fired power plants are somewhat surprising and run contrary to the expectation in previous literature of substitutability between renewables and coal-fired generation. I find evidence that coal plant capacity factors and renewable penetrations are positively associated, indicating that a higher renewable penetration results in greater utilization of coal-fired power plants. One potential explanation I considered for this result is that renewables are causing marginal coal plants to shut down to accommodate the newer fuel sources. Coal plant retirements have increased over the last 10 years, coinciding with a rise in both gas-fired and renewable generation. In 2012, for example, nearly 11 thousand megawatts of coal capacity was retired nationally, accounting for more than 3 percent of the entire coal fleet. An additional 7 thousand was retired in 2013. Coal plant shut-downs would eliminate the older plants from the short-run data, thus potentially skewing the capacity factors of the remaining coal plants upwards. However, I explore this explanation empirically by eliminating all of the PMUs that had any capacity retirements during the sample. I find that eliminating all plants that had a retirement during the sample period has little impact on the results, thus providing evidence that my original result is robust to attrition bias.

Though not what I expected, I believe the overall results can be reconciled with my original hypothesis. I suspect that renewables are having two separate impacts on fossil-fuel 
generators, which cause unexpected results in the short-run analysis I conducted. First, renewable generators are providing power primarily in a relatively narrow capacity factor range from 10 percent to 40 percent. Second, renewables are introducing variability into the electric grid, as I hypothesize above, which I believe is creating conditions for greater load following requirements for both natural gas combined cycle plants and natural gas combustion turbines. These two effects can have disparate impacts on fossil fuel capacity factors.

Figure 3 provides a graphical framework for how renewables enter the market and impact fossil fuel technologies. The figure shows the relationship between the average yearly capacity factor for the three technologies of interest - coal, natural gas combined cycle, and natural gas combustion turbines - and the cumulative capacity utilized at that capacity factor for the years 1990 and 2013. ${ }^{5}$ To create these charts I sorted all of the plants by their capacity factor and stacked them by adding their capacity together to show the cumulative number of gigawatts in the system. As the values move up the y-axis, the capacity is used less intensively. I have called the resulting curve in the figure the system capacity utilization curve. What is evident from these utilization curves is that over the period of analysis - when renewables grew rapidly - the electricity market changed markedly. From 1990 to 2013 system capacity for these three technologies increased to $593 \mathrm{GW}$ in 2013 from $351 \mathrm{GW}$ in 1990, a gain of nearly 67 percent. In 1990, coal served the vast majority of the load, with natural gas combustion turbines relegated largely to peak load in the top left area of the load curve. In that year, natural gas combined cycle and renewables were largely non-existent. By 2013, however, coal plants were more spread out along the load-duration curve. Natural gas and renewables took up a significant portion of the load, especially between the so-called shoulder area of the curve with capacity factors between

\footnotetext{
${ }^{5}$ Each line reflects one generating unit and does not indicate the amount of capacity contained in that unit.
} 
10 and 40 percent. Also notable is that the load duration curve flattened considerably, primarily because the new load is being served by lower capacity factor plants. The median capacity factor in 1990 was approximately 33.8 , but fell to 26.1 in 2013 . The utilization curve at the low and of the capacity factors also became more peaked, indicating there were a greater number of plants operating at less than 10 percent capacity factors in 2013 than there were in 1990. 
Figure 3: System capacity utilization by prime mover technology and year
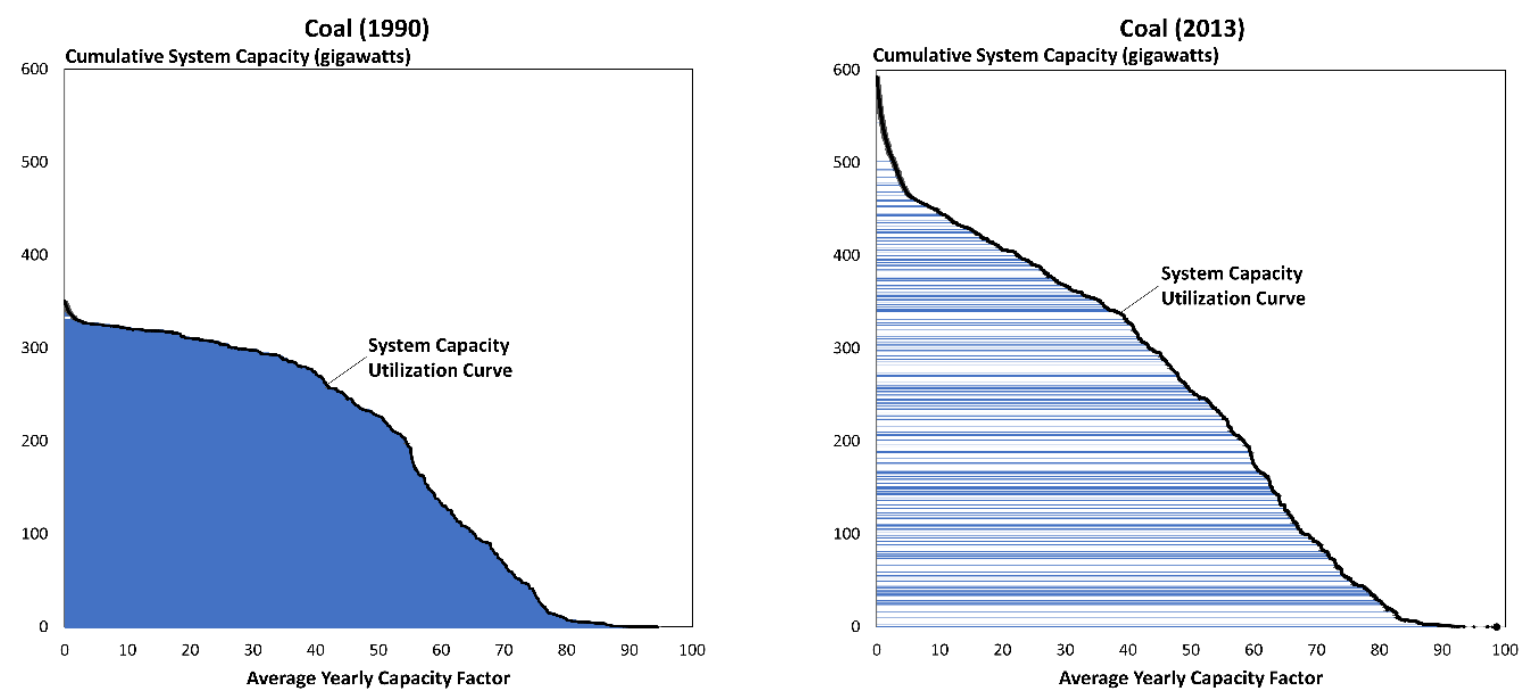

Natural Gas Combined Cycle (1990)
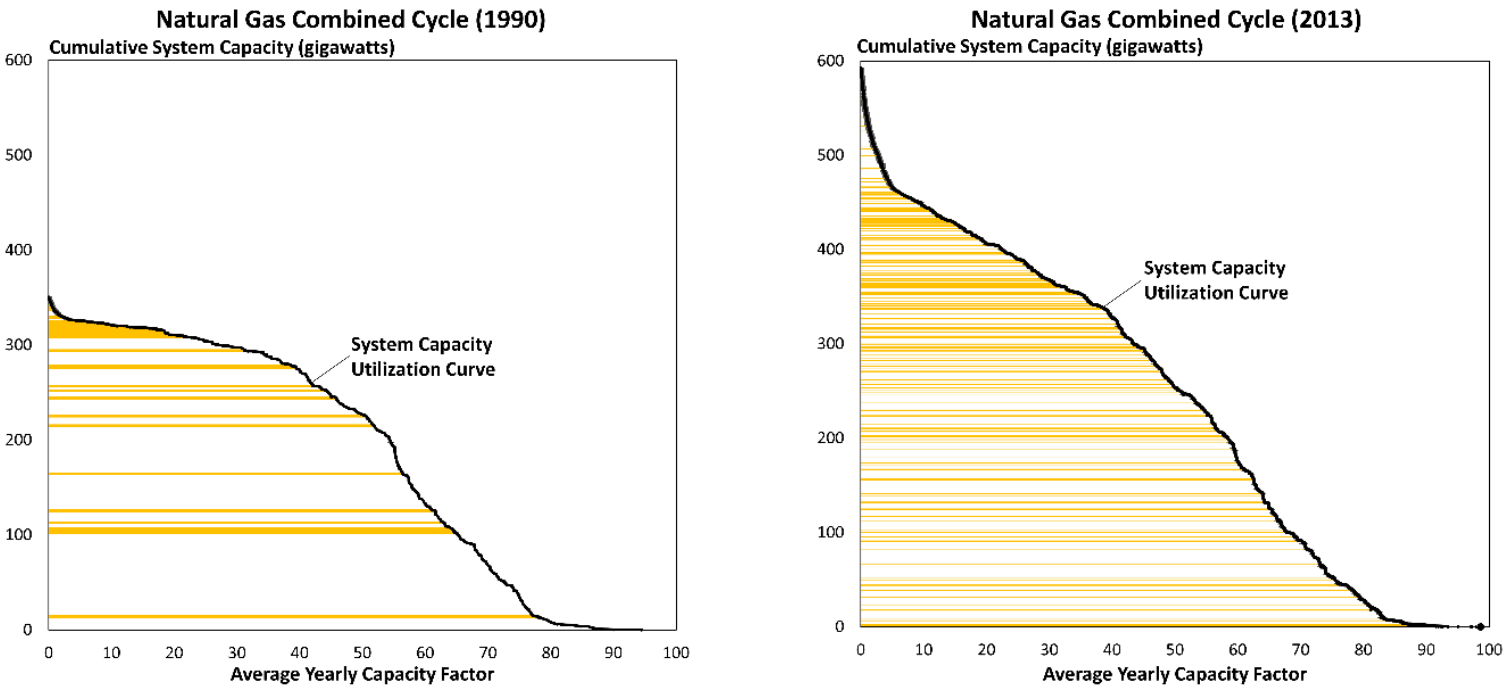

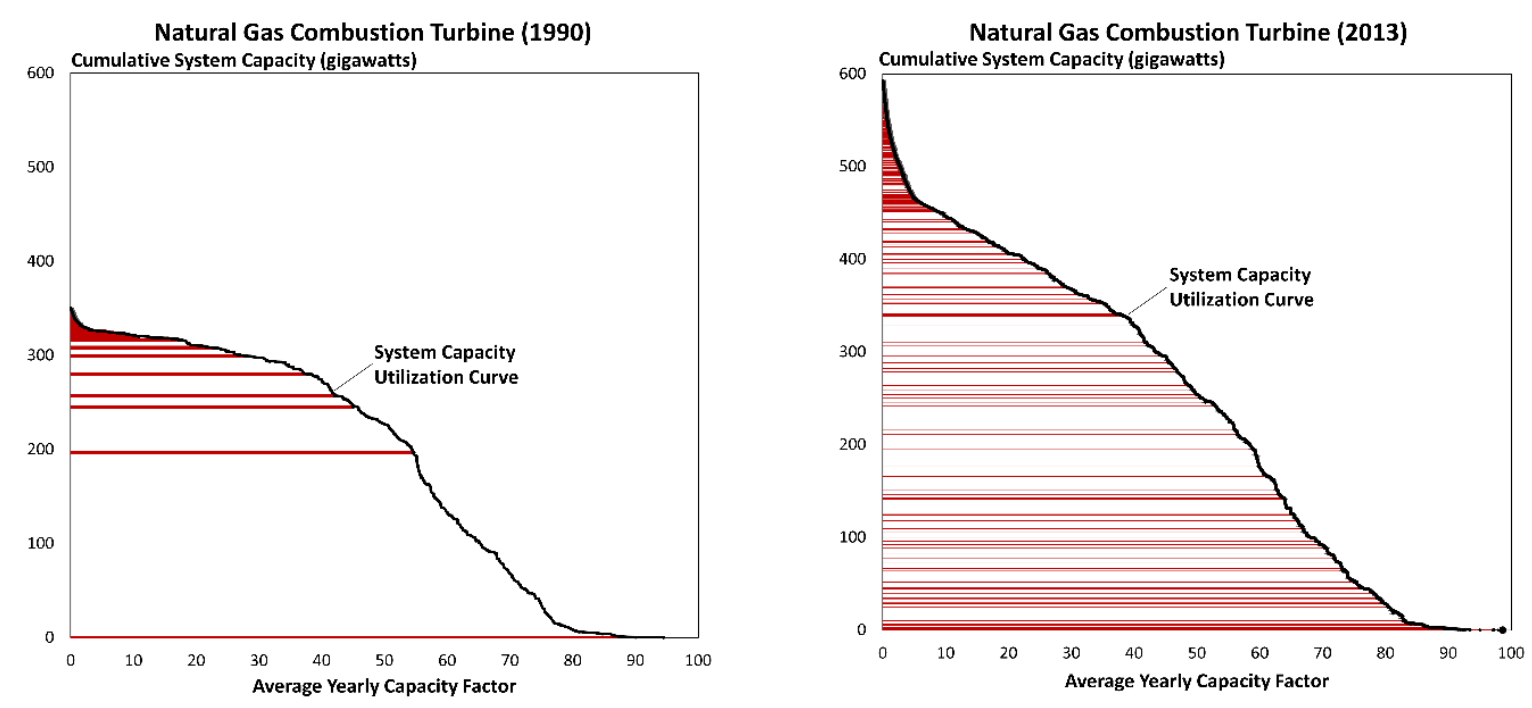

Source: Author calculations based on data from the US Energy Information Administration

These trends in the utilization curve can help explain the results I find in my regression analysis. I propose that during the time period of analysis, renewable generation plants increased variability in the generation supply, thus necessitating increases capacity that could follow load. This is evident in Figure 3 above, as the large majority of additional capacity added between 1990 and 2013 operates at capacity factors between 10 and 40. The amount of capacity operating at these lower capacity factors more than doubled in this time period to more than $118 \mathrm{GW}$ in 2013, from just over $49 \mathrm{GW}$ in 1990. Most of this increase in shoulder-area capacity was filled by natural gas combined cycle plants. NGCC plants also moved into the base load power area above 40 capacity factor. The spreading of natural gas combined cycle in particular could help explain why renewables and NGCC are not significantly related to one another, at least in the short run. At the same time, there was a massive increase in capacity that was run at less than a 10 capacity factor. The amount of capacity operating at less than 10 capacity factor rose to more than $147 \mathrm{GW}$ in 2013, from less than $30 \mathrm{GW}$ in 1990. Most of this demand was met with natural gas combustion turbines. I argue that this increase was due to a greater need for peak load 
generation and load following for rapid changes in demand. To the extent that this greater need for load following was caused by increases in renewables, gas combustion turbines could have had their capacity factors reduced on average as a result of new renewable generation. Combustion turbines also seem to have been pushed into the lower capacity factor range by an increase in natural gas combined cycle generation in the shoulder area. Lastly, natural gas combined cycle plants appear to have relieved small coal plants of the need to follow load at the lower end of the capacity factor scale. This, along with increased demand, could have had the effect of increasing the average capacity factors for coal plants. Indeed, average coal capacity factors weighted by capacity rose to 65.8 in the first decade of the 2000s from approximately 58.8 in the 1990s, before falling back somewhat after 2011.

I find evidence for my interpretation in a number of my regression results. First, my results indicate that natural gas combined cycle plants and combustion turbines are both being used for load following. I find a significant positive association between the number of cooling degree days in a state and capacity factors for both for natural gas combined cycle plants and gas combustion turbines. This result provides evidence that greater load following during peak demand periods is driving up capacity factors for NGCC generators as well as combustion turbines. Secondly, as I mention above, renewables are intermittent and thus they cannot be relied on for base load power generation. Average capacity factors weighted by capacity for solar and wind nationally in 2013 were approximately 0.18 and 0.32 respectively. While the average national capacity factor for natural gas plants was 0.4 in 2013, this was a period of extremely low gas prices. The average capacity factor since 1990 for natural gas generators is closer to 0.35 . In contrast, coal plants have had an average capacity factor of 0.61 over the last 24 years, though the national average capacity factor fell in 2013 to 0.54 because of competition from inexpensive 
gas generation. Because renewables tend to operate in the same capacity factor range as natural gas, they occupy the same shoulder area of the load curve as natural gas generators and thus are more likely to replace natural gas when operating than other technologies. This displacement of natural gas generation has potentially pushed NGCC plants higher on the load curve, which may be further displacing gas combustion turbines, which have a higher fuel cost (though also higher ramp rate). Secondly, renewables may also be correlated with electric load, which typically increases during the day, although this is more likely to be the case with solar generation than other forms of renewable generation. If renewables are more likely to produce power during peak times, it could reduce the need for dispatchable peak load generators. This could help explain why my results show no significant impact on capacity factors for NGCC plants, but a negative impact on capacity factors for gas combustion turbines.

If renewable generation is displacing natural gas generation while simultaneously driving gas to be used more for load following than base load power this could also explain the positive association between renewable generation shares and coal capacity factors. To the extent that renewable generation is causing natural gas combined cycle plants to be used for load following, coal plants could be taking up the extra base load power that would have been provided by

natural gas combined cycle plants. Since coal plants have been operating with some slack in their capacity factors, they could potentially take on additional load as renewables spread through the middle area of the load curve.

\section{Conclusions}

Though my interpretation of the results requires further research, it does suggest some basis for questioning the efficacy of renewable incentives for reducing carbon emissions, which is often one of their stated goals. These results provide some evidence that renewables may be 
coming into the fuel mix at the expense of natural gas plants, which have a lower carbon output than coal-fired power plants. Additionally, my results suggest that adoption of renewable generation is associated with increased capacity factors of coal plants but also with the retirement of some coal-fired capacity. Whether these retirement further the goal of reducing carbon emissions requires further investigation.

My analysis examines only the short-run trade-offs between renewables and fossil fuels, but does not consider the long-run investment decisions to add new renewable and natural gas capacity. In future research I plan to investigate the link between renewable and natural gas combined cycle capacity growth, and this further research into the role renewables play in natural gas investment decisions may indeed show complementarities between renewable and natural gas capacity that is not present in this short-run analysis. On the other side of the investment decision, I also believe further investigation is needed into the long-run effects of renewables on coal plant retirements. I explore the latter question of coal-fired power plant retirements in Chapter 3 of this dissertation. Another possible avenue to explore would be to explicitly model the additional volatility introduced into the electric grid by renewables.

Lastly, the rapid growth in natural gas production due to the advent of hydraulic fracturing and horizontal drilling technologies has potentially created a new paradigm in electricity markets. It is hard to determine whether the results found in this paper will be applicable going forward in an era when electricity can be produced nearly as cheaply from natural gas as from coal. 


\section{Chapter 2 Appendix}

This appendix describes in detail the data used in this chapter and the sources for the data. Most of the data in this chapter is publicly available from the US Energy Information Administration (EIA). The initial dataset contained 13,453 observations of individual Prime Mover Units (PMUs). Of this total, 114 observations were eliminated as outliers due to apparent data entry errors in the PMU's heat rate. Another 2,114 observations were dropped because of missing fuel cost data. Table 10 provides detailed descriptions and sources for each variable.

Table 10: Data description and sources

\begin{tabular}{|c|c|c|}
\hline Variable & Description & Source \\
\hline CAPFAC & Capacity factor of each PMU. & $\begin{array}{l}\text { EIA form EIA-860; EIA form EIA- } \\
923 \text { (and predecessor forms } 906 \\
\text { and 920); EIA-867 }\end{array}$ \\
\hline NERCRENSHARE & $\begin{array}{l}\text { Share of generation from renewable sources in the NERC } \\
\text { region in a given year. }\end{array}$ & $\begin{array}{l}\text { EIA forms EIA-923 (and } \\
\text { predecessor forms } 906 \text { and } \\
920 \text { ); EIA-867 }\end{array}$ \\
\hline RELFUELCOST & $\begin{array}{l}\text { Fuel cost faced by a given plant relative to the mean price } \\
\text { of alternative fuels in each year. }\end{array}$ & $\begin{array}{l}\text { EIA form EIA-923 (and } \\
\text { predecessor forms } 906 \text { and } \\
\text { 920); EIA Monthly Energy } \\
\text { Review }\end{array}$ \\
\hline PMUAGE & The average age of all generating units within each PMU. & $\begin{array}{l}\text { EIA forms EIA-923 (and } \\
\text { predecessor forms } 906 \text { and 920) }\end{array}$ \\
\hline COOLDEGDAYS & $\begin{array}{l}\text { The number of days in a particular state and year where } \\
\text { the temperature is above } 65 \text { degrees, multiplied by the } \\
\text { number of degrees above } 65 \text {. }\end{array}$ & $\begin{array}{l}\text { National Weather Service } \\
\text { heating and cooling degree days }\end{array}$ \\
\hline LCVSCORE & $\begin{array}{l}\text { The average of scores on the annual League of } \\
\text { Conservation Voters Scorecard for congressional } \\
\text { representatives and senators for each state and year. }\end{array}$ & $\begin{array}{l}\text { League of Conservation Voters } \\
\text { Scorecard }\end{array}$ \\
\hline
\end{tabular}




\title{
Chapter 3: Drivers of coal-fired capacity retirements in electricity markets
}

\begin{abstract}
Retirements of coal-fired electric generating capacity have become an increasing concern for policy makers in US electricity markets. The US Energy Information Administration projects that by 2020, as much as 50 gigawatts of coal capacity will be retired, representing 15 percent of coal plant capacity nationwide. Using a highly disaggregated dataset of plant-level data, this paper examines the drivers of coal-fired power plant retirements over the 1990-2013 time period, with a particular focus on renewable penetration and environmental policy. I find that the drivers of coal plant retirements are multi-faceted, stemming from changes in federal environmental policy as well as variation in the price of competing fuels. However, consistent with results in the previous chapter, I find that renewable penetration in a plant's NERC region reduces the likelihood of coal-plant retirement.
\end{abstract}

\section{Introduction}

Retirements of coal-fired electric generating capacity have become an increasing concern for policy makers in US electricity markets. Though coal capacity retirements have occurred regularly over the last 20 years, most retirements were small and had little impact on total coalfired capacity. Coal capacity retirements have accelerated in the past three years, however. Between 2011 and 2013, a total of almost 20 gigawatts of coal-fired capacity was retired, representing nearly 6 percent of the total capacity in that period (see Figure 4). The US Energy Information Administration projects that by 2020 another 50 gigawatts of coal-fired capacity could be retired, representing about 15 percent of the total coal-fired capacity in operation as of the end of 2013 (EIA 2014a). A number of researchers have been concerned that these capacity retirements could have adverse effects on the reliability of the electric grid (see for example Danish, Smith, and Gregg 2011, Fleischman et al. 2013, Burtraw et al. 2013). Despite these concerns, there exists little empirical literature examining the drivers of coal-fired capacity retirements. 
Figure 4: Coal capacity retirements and share of renewable generation

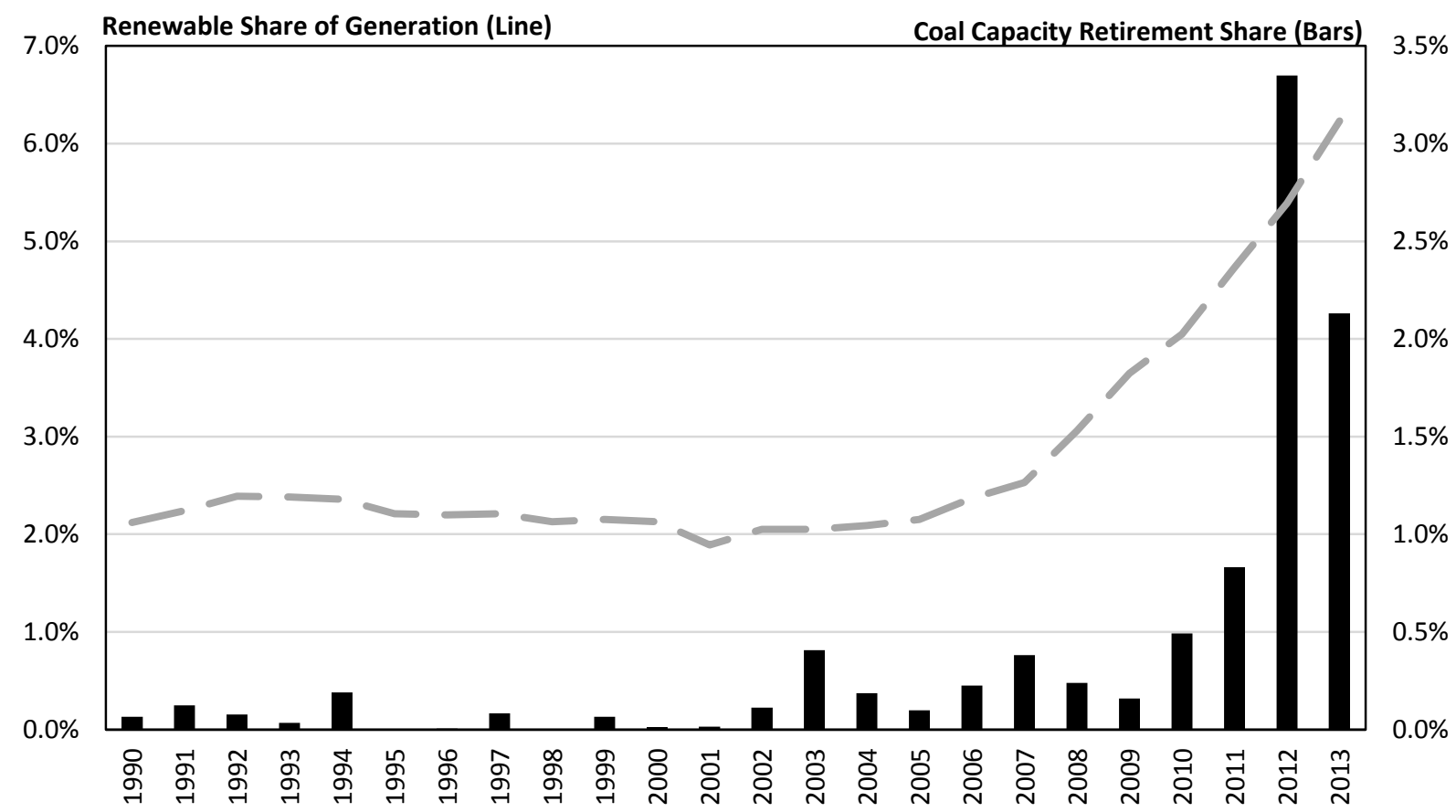

Source: Author calculations based on data from the US EIA

This paper examines several potential drivers of coal capacity retirements to estimate which are most prominent empirically, with a particular focus on renewable penetration on a NERC region level. This research in part stems from previous findings in Chapter 2 of this dissertation that renewable penetration is associated with increases in capacity factors for coalfired power plants. My contributions to the literature in this chapter are threefold. First, there is little if any direct empirical examination of coal capacity retirements. Much of the existing literature employs econometric simulation models to predict potential retirements in the future; however they do not attempt to explain coal retirements in the existing data. Second, I use a dataset with a high level of disaggregation that allows an examination of retirements at the subplant level. This allows for a particular focus on coal capacity, instead of including all generation at a particular plant. Lastly, the issue of whether renewable penetration is a driver of coal-plant retirements has not been previously examined in the literature. 
I find that the drivers of coal plant retirements are multi-faceted, stemming from changes in federal environmental policy as well as variation in the price of competing fuels. However, consistent with results in the previous chapter, I find that renewable penetration in a plant's NERC region reduces the likelihood of plant retirements.

\section{Literature review}

A variety of papers have examined the question of power plant retirements. Early studies tended to find that coal-fired power plant retirements were not a major issue in electricity markets. Ellerman (1996), for example, found that coal plants competed well with natural gas plants because their marginal costs were comparable, despite larger sunk capital costs for coal plants. As recently as 2007, Fabrizio, Rose, and Wolfram (2007) dismissed retirements as a major issue in electricity markets because up to that point they had been fairly rare. Indeed, until recently the issue of retirements was a concern more for nuclear power plants, which in many ways are similar to coal plants in that they function as base load power. Rothwell (2000) modeled the early shut-down decisions for nuclear plants, and found, unsurprisingly, that marginal costs are an important consideration in shut-down decisions.

The issue of coal plant retirements has become more relevant in recent years as shutdowns have become more pronounced. Much of the discussion in the literature has focused on assessing the impact of federal environmental policy, particularly the impact of the Mercury and Air Toxics Standards (MATS), which were finalized in 2011. Beasley et al. (2013) provided a comparison of nine econometric simulation studies of federal environmental regulation, with a particular focus on MATS. The study concluded that the impact on coal capacity from MATS regulations was expected to be substantially smaller than many studies were predicting. Burtraw et al. (2012) examined the effect of MATS and another federal policy, the Cross State Air 
Pollution Rule. They concluded that economic factors, such as the recent recession and falling natural gas prices due to increased supplies of shale gas, were expected to have a greater impact on coal retirements than environmental policy. However, both of these studies primarily used econometric simulation models to forecast potential retirements. Craig and Savage (2013) recognized the potential of attrition bias among electric generating plants. Though the paper primarily examined the efficiency gains of electricity restructuring, the authors used a two-part estimation process with a probit model in the first stage to incorporate the probability of attrition into their model. The probit model is similar to the model that I use in this paper to estimate retirements.

Shut-down decisions have been examined in other manufacturing contexts. Olley and Pakes (1996) was one of the first studies to explicitly estimate shutdown decisions using data from the US telecommunications industry. The authors found that capital was reallocated to more productive plants through the decision for less-productive plants to exit the market. Disney et al (2003) modeled exit times and estimated hazard rates for firms entering and exiting the market in the United Kingdom. Lastly, Syverson (2004) discussed why suppliers had wide variation in productivity between different plants. His results suggested that greater substitutability across space - for example more densely packed supply chains - could provide incentives for firms with higher costs to exit the market.

\section{Methodology}

In Chapter 2 of this dissertation, I examine the impact of renewable penetration on capacity factors for coal-fired power plants. My results indicate, to my surprise, that an increase in renewables in a power plant's NERC region was positively associated with capacity factors for coal-fired power plants. This finding seems to indicate that renewables are not displacing 
coal generation in the short run, but are instead moving into the shoulder area of the load curve, currently occupied by generation from natural gas combined cycle and gas combustion turbines. In this chapter, I assess the potential for renewable generation to influence coal-fired power plant retirements. Power plant retirements can be viewed as the culmination of the lifecycle of a power plant. The retirement thus indicates that certain conditions are present that reduce the plant's profitability to the point where it becomes necessary to shut down the plant. If, as my results show in Chapter 2, renewables are indeed increasing capacity factors for coal-fired plants, I would expect coal plants to become more profitable, and thus less likely to retire.

To examine this question, I specify a duration model that measures the length of time until retirement, conditional on plant-level factors. Several previous studies in other areas have employed duration models for firm exits (see for example Disney, Haskel, and Heden 2003, Dunne, Roberts, and Samuelson 1989, Boeri and Bellmann 1995). A duration model is typically defined using a hazard function, which measures the probability of leaving an initial state. In this chapter, the initial state is the operation of the power plant, and the hazard is the probability of retirement. In the typical duration model, the data is assumed to be cross-sectional with the duration of the observation measured as a continuous variable over a relatively short period of time (Wooldridge 2002). Covariates are thus static relative to the observed duration of the dependent variable. As Wooldridge points out, special care must be taken to handle covariates that change over time. The data used in this study is measured from 1990 to 2013, and the covariates in the panel data change considerably over this time period. McCall (1994) suggests that in the presence of time-varying covariates, a discrete time model specification can be preferable to a continuous time model. 
In addition to issues regarding time-variant covariates, the data used in this study pose additional complications. First, they are measured on a yearly basis, which I believe precludes them from being interpreted as approximating continuous time. Allison (1982) indicates that treating observations measured yearly as continuous is problematic, as the unit of measurement cannot be thought of as instantaneous change in time. Second, in the power plant data used in this study, retirements occur after a long period of time, as many as several decades. The median in-service date of the coal plants used in this study is 1968 , for example, with the earliest plant built in 1921. In order to account for these deviations from the standard duration model, I instead estimate a discrete time duration model, as suggested in Allison (1982) and Jenkins (1995). Following Allison, I define a discrete time hazard function as follows:

$$
P_{i t}=\operatorname{Pr}\left[T_{i}=t \mid T_{i} \geq t, x_{i t}\right]
$$

Under this formulation, $T_{i}$ is a random variable giving the time when the retirement occurs, and $P_{i t}$ is the probability of plant $i$ to retire in time period $t$, conditional on $T_{i}$ being after or equal to the current time period, and other covariates $\left(x_{i t}\right)$. As Allison indicates, the log likelihood function for this estimation can be defined as a function of the hazard function as follows:

$$
\log (L)=\sum_{i=1}^{n} \sum_{j=1}^{t_{i}} y_{i t} \log \left[\frac{P_{i j}}{1-P_{i j}}\right]+\sum_{i=1}^{n} \sum_{j=1}^{t_{i}} \log \left[1-P_{i j}\right]
$$

which is equivalent in form to the log-likelihood function for dichotomous dependent variables. Thus discrete-time duration models can be estimated using binary-choice methods with each observation in the panel treated as a separate indicator of the survival of the observed individual plant in that given time period. This type of model has the added benefit of easily accommodating time-variant covariates, as these are simply incorporated into the model as independent regressors for each observation. 
Though many economics studies prefer the probit model for limited dependent estimation, much of the survival analysis literature uses the logit model as the primary estimator for discrete time data. For this reason, I have chosen the logit model as the primary estimator for this study. ${ }^{6}$ The model specification used in this study follows standard logit assumptions. Each plant operator makes a decision whether to retire capacity based on whether their expected profits $(\pi)$ from that capacity in the current time period are below some threshold level $(\alpha)$. Profitability is determined by a number of PMU-, state-, and NERC-level variables.

$$
\pi_{i t}=x_{i t} \beta+u_{i t}
$$

The expected profitability and the minimum level of profitability required to remain in operation is unobserved, and thus is treated as a latent variable in the logit estimation. I then specify the logit model as follows:

$$
\operatorname{Pr}\left(\pi_{i t}<\alpha \mid x_{i t} \beta\right)=\operatorname{Pr}\left(y_{i t}=1 \mid x_{i t}\right)=\Lambda\left(x_{i t} \beta\right)=\frac{\exp \left(x_{i t} \beta\right)}{1+\exp \left(x_{i t} \beta\right)}
$$

This probability density yields a log-likelihood function of the form:

$$
\ln (L)=\sum_{i=1}^{n}\left\{y_{i t} \ln \left[\Lambda\left(x_{i t} \beta\right)\right]+\left(1-y_{i t}\right) \ln \left[1-\Lambda\left(x_{i t} \beta\right)\right]\right\}
$$

The observed dependent variable $\left(y_{i t}\right)$ is the retirement of the PMU, expressed as the indicator variable RETIRED, which takes on a value of 1 if any of the capacity in a particular PMU is retired in that year, and zero if all of the capacity in the PMU is still in operation. Despite an increase in coal-fired capacity retirements over the last two years, there are a relatively small number of retirements in any given year. Out of 11,225 observations of coalfired power plant PMUs over 24 years in the sample, there are 197 observations where there was

\footnotetext{
${ }^{6}$ As a robustness check, I also estimate a probit model, and the results are similar.
} 
a recorded retirement, representing 1.8 percent of the entire sample. See Table 11 for summary statistics. This creates a highly censored dataset with mostly zero observations.

Table 11: Summary statistics

\begin{tabular}{lcccccc}
\hline \multicolumn{1}{c}{ Variable } & $\begin{array}{c}\text { Number of } \\
\text { Observations }\end{array}$ & Mean & $\begin{array}{c}\text { Standard } \\
\text { Deviation }\end{array}$ & Median & Minimum & Maximum \\
\hline RETIRED & 11,225 & 0.01 & 0.12 & 0.0 & 0.0 & 1.0 \\
RETIREDCAP & 11,225 & 2.33 & 31.54 & 0.0 & 0.0 & $1,728.0$ \\
NERCRENSHARE & 11,225 & 0.02 & 0.03 & 0.02 & 0.0 & 0.17 \\
RELFUELCOST & 11,225 & 0.38 & 0.16 & 0.36 & 0.05 & 1.42 \\
RELHEATRATE & 11,225 & 1.54 & 1.36 & 1.1 & 0.0 & 13.26 \\
COOLDEGDAYS & 11,225 & 1.12 & 0.72 & 0.91 & 0.04 & 3.8 \\
LCVSCORE & 11,225 & 0.44 & 0.19 & 0.42 & 0.0 & 1.0 \\
MERCCOMP & 11,225 & 0.87 & 0.34 & 1.0 & 0.0 & 1.0 \\
MATS & 11,225 & 0.14 & 0.34 & 0.0 & 0.0 & 1.0 \\
\hline
\end{tabular}

My primary independent variable for both estimations is the percentage of renewable energy within each region of the North American Electric Reliability Corporation (NERC) where the PMU is located (NERCRENSHARE). I am also interested in the impact on retirement decisions of fuel costs for coal-fired power plants relative to their primary competing fuel, natural gas. RELFUELCOST is price of fuel faced by the coal plant in each year measured in dollars per million British thermal units (MMBtu) divided by the mean price per MMBtu for natural gas in that year. The PMU-level fuel cost variable was calculated from EIA-923 (2013b) and FERC Form 423 (2011) for historical data. The mean fuel cost for natural gas plants come from the EIA Monthly Energy Review (2014c). Due to data restrictions, the fuel cost was unavailable for some plants in some years. In these cases, I calculated the average heat rate for the type of fuel and prime mover technology and assigned that heat rate to plants of similar age. I then multiplied by the average fuel price for the current calendar year. I would expect that as the own-price of fuel for coal plants rises relative to a natural gas, the probability of retirement will 
rise. I also control for the power plant's efficiency relative to other coal-fired power plants (RELHEATRATE). This is measured by dividing the plant's heat rate, which is a measure of the number of Btu's needed to produce one kilowatt hour $(\mathrm{kWh})$ of power output, by the average heat rate in that year. As a plant's heat rate rises relative to the average, indicating lower efficiency, I would expect the probability of retirement to rise. To assess the impact of federal MATS regulations, I include an indicator variable that equals one in the years since MATS has been finalized. I interact this variable with an indicator for whether the plant has scrubbing equipment that can be used as a compliance strategy for mercury mitigation (MERCCOMP). Plants have been required to report mercury compliance strategies only since 2013; however, the plants' scrubbing technologies have been reported for all years of the dataset. For the years prior to 2013 , I assume that a plant is mercury compliant if it has scrubbing technologies that are considered mercury compliance strategies in the 2013 data. $^{7}$

In addition to the primary regressors, I also control for a number of other factors. To measure environmentalist sentiment, I use the average score on the League of Conservation Voters Scorecard (LCVSCORE) (LCV 2013), which is a measure of how the votes of each member of the US Congress coincide with the interests of the LCV. I take the mean of the scores for each state's legislators to derive the average state score. I also control for electricity demand by utilizing cooling degree days (COOLDEGDAYS). This data from the National Weather Service (NWS 2014) measures the number of days and degrees the temperature in a state is above 65 degrees. Finally, in some specifications, I include fixed effects for the PMU and/or year. These variables help account for differences in regulatory environment across regions and time.

\footnotetext{
${ }^{7}$ See chapter appendix for more information on the technologies that meet this standard.
} 
In addition to estimating the probability of retirements using the logit model, I also estimate the extent to which renewable penetration is responsible for capacity retirements using a Tobit model. The Tobit model has similar assumptions to the logit model, in that the expected profitability of the plant is not observed, and thus is treated as a latent variable in the observed retirement of PMU capacity. However, the model incorporates both the probability of retirement and the amount of capacity reduction to estimate the degree of retirements once the threshold of lower profitability is reached. The Tobit formulation indicates a log-likelihood function of the following form:

$$
\ln [L(\beta, \sigma)]=\sum_{i=1}^{N} 1\left(y_{i t}=0\right) \ln \left[1-\Phi\left(\frac{x_{i t} \beta}{\sigma}\right)\right]+1\left(y_{i t}>0\right) \ln \left[\frac{1}{\sigma} \phi\left(\frac{y_{i t}-x_{i t} \beta}{\sigma}\right)\right]
$$

where $y_{i t}$ is the primary dependent variable calculated as the sum of retired capacity for each PMU in a given year (RETIREDCAP). The independent variables $\left(x_{i t}\right)$ are the same as in the Logit model above.

\section{Data}

The data used in this study is drawn primarily from the Energy Information Administration EIA-860 (EIA 2013a), and EIA-923 (EIA 2013b). Using this data for plant-level analysis of electricity markets is not new. Both Fabrizio et al (2007) and Hiebert (2002) used these plant-level data to examine the efficiency of coal-fired power plants through the use of plant-level heat-rate measurements. However, in each case there was the potential for the introduction of measurement error, as aggregation to a plant requires assigning a primary fuel for each plant, which may be difficult at plants with multiple fuel sources. In this study, I combine capacity data, which is reported for each generating unit within a plant, with generation data that is aggregated by fuel and prime mover. As each observation may include multiple generating 
units that use the same fuel and prime mover technology, I have adopted the term "prime mover unit" (PMU) to refer to the units of analysis in this study. The resulting dataset is a yearly unbalanced panel of power plant variables for the years 1990-2013 disaggregated by plant, fuel and prime mover. Data on the environmental control systems comes from EIA-923 (EIA 2013b), and EIA-767 (EIA 2005) forms for historical data.

\section{Results}

Table 12 shows the results for the logit estimations of Equation (15). Model 1 constitutes the base model with all covariates and no fixed effects. Model 2 does not control directly for the MATS rules, instead controlling for the rules only through an interaction with a PMU's mercury compliance. I specified this model because the MATS rules came into effect in 2011 and thus the MATS dummy variable is troublesome econometrically as it is extremely collinear with the dependent variable. However, this model, along with models 3 and 4, does include a control for mercury compliance, which has been interacted with MATS. Model 3 adds fixed effects for the year and model 4 includes both year and NERC region fixed effects. Again, these two models do not include a control for the MATS rules directly, as the dummy variable for MATS would be perfectly collinear in a given year. The last two models (models 5 and 6) are fixed effects and random effects models, respectively, which include controls for the PMU and year. 
Table 12: Logit regression estimates

\begin{tabular}{|c|c|c|c|c|c|c|}
\hline \multicolumn{7}{|c|}{ Dependent variable: RETIRED } \\
\hline & $\begin{array}{l}\text { Model 1: } \\
\text { Base Model }\end{array}$ & $\begin{array}{c}\text { Model 2: } \\
\text { Without MATS }\end{array}$ & $\begin{array}{c}\text { Model 3: } \\
\text { Year Fixed Effects }\end{array}$ & $\begin{array}{c}\text { Model 4: } \\
\text { Year and NERC Fixed } \\
\text { Effects }\end{array}$ & $\begin{array}{c}\text { Model 5: } \\
\text { Year and PMU } \\
\text { Random Effects } \\
\end{array}$ & $\begin{array}{c}\text { Model 6: } \\
\text { Random Effects } \\
\text { without MATS } \\
\end{array}$ \\
\hline NERCRENSHARE & $-0.055(0.092)$ & $0.078(0.007)$ & $-0.144(0.000)$ & $-0.117(0.048)$ & $-0.033(0.238)$ & $0.074(0.003)$ \\
\hline RELFUELCOST & $0.008(0.324)$ & $0.034(0.000)$ & $0.013(0.179)$ & $0.012(0.209)$ & $0.005(0.433)$ & $0.027(0.000)$ \\
\hline RELHEATRATE & $-0.003(0.000)$ & $-0.002(0.060)$ & $-0.004(0.000)$ & $-0.004(0.000)$ & $-0.002(0.001)$ & $-0.001(0.088)$ \\
\hline COOLDEGDAYS & $-0.002(0.322)$ & $-0.002(0.259)$ & $-0.005(0.070)$ & $-0.004(0.271)$ & $-0.001(0.413)$ & $-0.002(0.350)$ \\
\hline LCVSCORE & $0.023(0.000)$ & $0.013(0.043)$ & $0.020(0.003)$ & $0.022(0.004)$ & $0.020(0.000)$ & $0.012(0.037)$ \\
\hline MERCCOMP & $-0.063(0.000)$ & $-0.022(0.000)$ & $-0.037(0.000)$ & $-0.037(0.000)$ & $-0.058(0.000)$ & $-0.019(0.000)$ \\
\hline MATS & $0.077(0.000)$ & & & & $0.070(0.000)$ & \\
\hline Pseudo R2 & 0.142 & 0.100 & 0.196 & 0.197 & & \\
\hline Hausman & & & & & 53.31 & 59.08 \\
\hline$A I C$ & $1,472.6$ & $1,541.3$ & $1,408.3$ & $1,424.0$ & $1,468.3$ & $1,536.8$ \\
\hline
\end{tabular}


I find mixed results for the effect of the renewable share in a PMU's NERC region on the hazard rate of retirement for that PMU. Based on a 5 percent significance level, the marginal effect of NERCRENSHARE is not significantly different from zero in both models where the MATS rules are accounted for directly (models 1 and 5). In models 2 and 6, which account for MATS only through interaction, the marginal effect of NERCRENSHARE is positive and significant, indicating that an increase in the share of renewables would increase the hazard rate for coal-plant retirements. However, in models 3 and 4, where year and NERC fixed effects are included, the marginal effect of NERCRENSHARE is significant and negatively associated with the hazard rate for retirement.

Coal plants' fuel cost relative to natural gas (RELFUELCOST) is positively associated with plant retirements in two of the models, but the marginal effects are not significant in the other four model specifications. The lack of significance of the relative fuel cost may be largely explained by the fact that the majority of variation in this variable is attributable to yearly market changes in the price of natural gas and coal, rather than individual variation between power plants. For example, citygate natural gas prices almost tripled from \$2.95 per MMBtu in 1990 to $\$ 8.94$ per MMBtu in 2008, before falling back to $\$ 4.76$ in 2013. Meanwhile, average market prices for coal rose from $\$ 1.33$ per MMBtu in 1990 to $\$ 3.54$ in 2011. Thus both the numerator and denominator of this ratio were affected by overall market price fluctuations. Because of this, there is significant collinearity between this variable and yearly fixed effects and/or the MATS variable, which does not vary within each year. My results show a significant negative association between RELHEATRATE and the hazard rate for plant retirements that is present in all of the specified models. I expected that a higher heat rate, which is a marker of low efficiency, would be positively correlated with retirements. This effect is quite small, however, 
as an increase of 1 in RELHEATRATE - indicating an order of magnitude increase in a plant's heat rate relative to other coal plants - would reduce the probability of retirement by only 0.3 percent on average. Marginal effects for COOLDEGDAYS are not significant in any of the models, and LCVSCORE is positively associated with the hazard rate for plant retirements, but is small. In both models that explicitly account for the MATS rules, the presence of the MATS regulation increases the hazard rate for plant retirement. And mercury compliance $(M E R C C O M P)$ has a significant negative association with plant retirements in all model specifications.

Tobit results are presented in Table 13. Model 1 again indicates a non-significant marginal effect of NERCRENSHARE with the coal-fired power plant retirements. However, like model 4 in the logit models, model 2 does indicate a significant negative association between capacity retirements and the share of renewables. Again the magnitude of the effect is relatively small; a 10 percent increase in renewable share would result in an increase in a reduction of retirements (increase in capacity) of approximately $167 \mathrm{MW}$. The coefficient on RELFUELCOST and COOLDEGDAYS are both not significant, while RHEATRATE has a small negative effect on capacity retirements. LCVSCORE has a positive association with capacity retirements and mercury compliance is negatively associated with capacity retirements, though the magnitudes are similar. 
Table 13: Tobit regression results

\begin{tabular}{lcc}
\hline Dependent variable: RETIREDCAP & \\
\hline & $\begin{array}{c}\text { Model 1: } \\
\text { Base Tobit }\end{array}$ & $\begin{array}{c}\text { Model 2: } \\
\text { Tobit with Year } \\
\text { Fixed Effects }\end{array}$ \\
\hline NERCRENSHARE & $-547.014(0.198)$ & $-1,665.032(0.000)$ \\
RELFUELCOST & $79.372(0.424)$ & $192.624(0.097)$ \\
RELHEATRATE & $-40.070(0.000)$ & $-53.509(0.000)$ \\
COOLDEGDAYS & $-24.168(0.333)$ & $-52.318(0.060)$ \\
LCVSCORE & $283.023(0.000)$ & $235.360(0.004)$ \\
MERCCOMP & $-286.061(0.000)$ & $-383.970(0.000)$ \\
MATS & $372.364(0.000)$ & \\
Pseudo $\boldsymbol{R}^{2}$ & 0.070 & 0.100 \\
AIC & $3,444.3$ & $3,373.0$ \\
\hline
\end{tabular}

Note: Reported coefficients are marginal effects. P-values in parenthesis.

\section{Conclusions}

The results above provide evidence that the drivers of coal-fired power plant retirements are multi-faceted. In some models, increases in the relative price between natural gas and coal have a significant impact on plant retirements. Federal MATS rules also appear to have a significant role in coal-plant retirements. In both models where MATS is controlled for explicitly, the presence of these regulations increases the likelihood of plant retirement by 7 percent. Mercury compliance (MERCCOMP) also plays a significant role in reducing coal-plant retirements in all model specifications. Plants with mercury-compliant scrubbing technologies are between 2 and 6 percent less likely to retire than other coal plants. This holds true both individually and in interaction with MATS rules.

The results above give conflicting evidence on the effect of renewable penetration on coal-fired power plant retirements. The marginal effect of NERCRENSHARE is not statistically significant in the two models where the MATS rules are accounted for directly. However, as I mentioned above, the MATS variable has little variation across years, and thus can be 
problematic econometrically. In models where MATS is introduced through an interaction term, the renewable share becomes significant again. The results also have positive signs on the coefficient for NERCRENSHARE in two of the model specifications. However, there is evidence that models 3 and 4 more accurately describe the data. P-values on the year and NERC fixed effects, respectively, show these coefficients are mostly significant, and likelihood ratio (LR) tests on these models compared with model 2 , indicate that these fixed effects provide important information in the estimation. Though these two models cannot be directly compared with model 1 using an LR test because they are not nested, tests using the Akaike Information Criterion (AIC) (for detailed derivation see Burnham and Anderson 2002) provide evidence that the fixed effects models are more likely to approximate the true data generating process.

My preferred results indicate a somewhat counterintuitive result. The marginal effects can be interpreted as stating that an increase in the share of renewable generation would lead to a decrease in the hazard rate for coal-fired power plant retirements (the Tobit models also provide a similar interpretation). The magnitude of this change is relatively small; an increase in the share of generation from renewables of 10 percentage points would reduce the probability of coal plant retirement by between 1.2 and 1.4 percent. Yet these findings provide evidence for the conclusion that renewables are not displacing coal-fired generation, and may in fact be enhancing it.

These results are consistent with those found in Chapter 2 of this dissertation, which finds that that renewable generation is positively associated with capacity factors for coal-fired power plants. Increased capacity factors in base load power plants should lead to greater profitability, thus reducing the likelihood of retirement. This is a surprising result, as much of the previous literature suggests that rising renewable generation should reduce the amount of generation from 
coal. But it gives further support to the hypothesis that renewables may in fact be taking a position on the load curve similar to that of natural gas plants. Increased variability in the load may also be allowing coal plants to step in to provide additional base load power as natural gas combined cycle plants are used more for load following. This hypothesis requires further research. 


\section{Chapter 3 Appendix}

This appendix describes in detail the data used in this chapter and the sources for the data. Most of the data in this chapter is publicly available from the US Energy Information Administration (EIA). The initial dataset contained 13,453 observations of individual Prime Mover Units (PMUs). Of this total, 114 observations were eliminated as outliers due to apparent data entry errors in the PMU's heat rate. An Additional 2,114 observations were dropped because of missing fuel cost data. Table 14 provides detailed descriptions and sources for each variable.

Table 14: Data description and sources

\begin{tabular}{|c|c|c|}
\hline Variable & Description & Source \\
\hline RETIRED & $\begin{array}{l}\text { Indicator variable for whether a PMU had any amount of } \\
\text { retired capacity in the given year. }\end{array}$ & EIA form EIA-860 \\
\hline RETIREDCAP & Amount of retired capacity in the given year. & EIA form EIA-860 \\
\hline NERCRENSHARE & $\begin{array}{l}\text { Share of generation from renewable sources in the NERC } \\
\text { region in a given year. }\end{array}$ & $\begin{array}{l}\text { EIA forms EIA-923 (and } \\
\text { predecessor forms } 906 \text { and } \\
\text { 920); EIA-867 }\end{array}$ \\
\hline RELFUELCOST & $\begin{array}{l}\text { Fuel cost faced by a given plant relative to the mean } \\
\text { citygate natural gas price in each year. }\end{array}$ & $\begin{array}{l}\text { EIA form EIA-923 (and } \\
\text { predecessor forms } 906 \text { and } \\
\text { 920); EIA Monthly Energy } \\
\text { Review }\end{array}$ \\
\hline RELHEATRATE & $\begin{array}{l}\text { Plant's heat rate relative to the mean heat rate for all coal- } \\
\text { fired power plants in each year as reported by the US EIA. }\end{array}$ & $\begin{array}{l}\text { EIA forms EIA-923 (and } \\
\text { predecessor forms } 906 \text { and } \\
\text { 920); EIA Monthly Energy } \\
\text { Review }\end{array}$ \\
\hline COOLDEGDAYS & $\begin{array}{l}\text { The number of days in a particular state and year where } \\
\text { the temperature is above } 65 \text { degrees, multiplied by the } \\
\text { number of degrees above } 65 \text {. }\end{array}$ & $\begin{array}{l}\text { National Weather Service } \\
\text { heating and cooling degree days }\end{array}$ \\
\hline LCVSCORE & $\begin{array}{l}\text { The average of scores on the annual League of } \\
\text { Conservation Voters Scorecard for congressional } \\
\text { representatives and senators for each state and year. }\end{array}$ & $\begin{array}{l}\text { League of Conservation Voters } \\
\text { Scorecard }\end{array}$ \\
\hline
\end{tabular}




\begin{tabular}{|c|c|c|}
\hline Variable & Description & Source \\
\hline MERCCOMP & 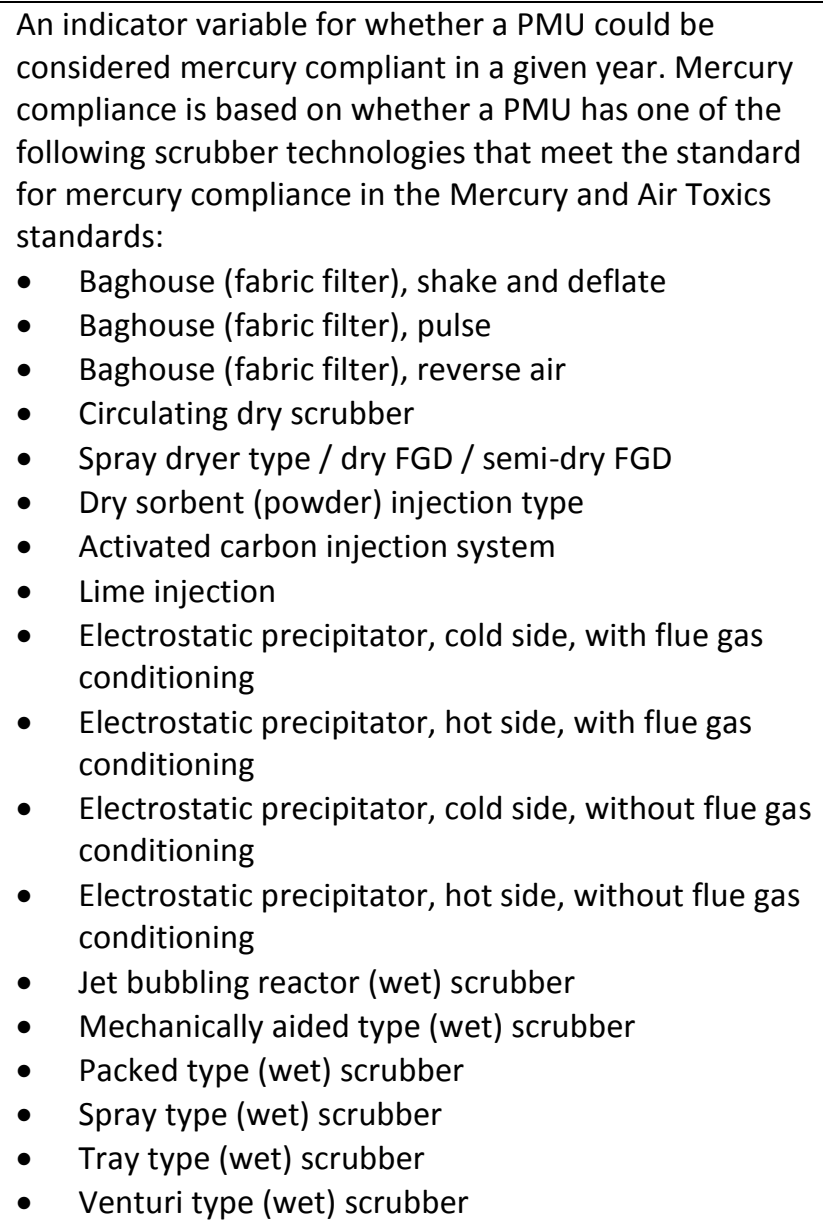 & $\begin{array}{l}\text { EIA form EIA-923 (and } \\
\text { predecessor forms 906/920). } \\
\text { Historical data comes from EIA- } \\
767 .\end{array}$ \\
\hline MATS & $\begin{array}{l}\text { An indicator variable representing the years after the } \\
\text { finalization of the Mercury and Air Toxics Standards. } \\
\text { Equals } 1 \text { in years } 2011 \text { and later. }\end{array}$ & None \\
\hline
\end{tabular}




\section{References}

Allison, Paul D. 1982. "Discrete-Time Methods for the Analysis of Event Histories."

Sociological Methodology 13:61-98. doi: 10.2307/270718.

Beasley, Blair, Matt Woerman, Anthony Paul, Dallas Burtraw, and Karen Palmer. 2013. Mercury and Air Toxics Standards Analysis Deconstructed: Changing Assumptions, Changing Results. Resources For the Future, Discussion Papers.

Bird, Lori, Caroline Chapman, Jeff Logan, Jenny Sumner, and Walter Short. 2011. "Evaluating renewable portfolio standards and carbon cap scenarios in the U.S. electric sector." Energy Policy 39 (5):2573-2585. doi: 10.1016/j.enpol.2011.02.025.

Black \& Veach. 2012. Cost and Performance Data for Power Generation Technologies. National Renewable Energy Laboratory.

Boeri, Tito, and Lutz Bellmann. 1995. "Post-entry behaviour and the cycle: Evidence from Germany." International Journal of Industrial Organization 13 (4):483-500. doi: http://dx.doi.org/10.1016/0167-7187(95)00501-3.

Burnett, J. Wesley, and Xueting Zhao. 2014. "Spatially Explicit Prediction of Wholesale Electricity Prices." 37th IAEE International Conference, New York, NY.

Burnham, Kenneth P., and David R. Anderson. 2002. Model Selection and Multi-Model Inference : A Practical Information-Theoretic Approach (2nd Edition). Secaucus, NJ, USA: Springer.

Burtraw, Dallas, Karen Palmer, Anthony Paul, Blair Beasley, and Matt Woerman. 2013. "Reliability in the U.S. electricity industry under new environmental regulations." Energy Policy 62 (0):1078-1091. doi: http://dx.doi.org/10.1016/j.enpol.2013.06.070.

Burtraw, Dallas, Karen Palmer, Anthony Paul, and Matt Woerman. 2012. "Secular Trends, Environmental Regulations, and Electricity Markets." The Electricity Journal 25 (6):3547. doi: http://dx.doi.org/10.1016/j.tej.2012.06.010.

Carley, Sanya. 2009. "State renewable energy electricity policies: An empirical evaluation of effectiveness." Energy Policy 37 (8):3071-3081. doi: 10.1016/j.enpol.2009.03.062.

Chen, Cliff, David White, Tim Woolf, and Lucy Johnston. 2003. "The Maryland renewable portfolio standard: An assessment of potential cost impacts." Synapse Energy Economics, Inc 17.

Craig, J. Dean, and J. Savage Scott. 2013. "Market Restructuring, Competition and the Efficiency of Electricity Generation: Plant-level Evidence from the United States 1996 to 2006." The Energy Journal Volume 34 (1). doi: http://dx.doi.org/10.5547/01956574.34.1.1.

Danish, Kyle W., Douglas W. Smith, and Kaitlin A. Gregg. 2011. "Upcoming EPA Regulations and Potential Impacts on Electric Reliability." The Electricity Journal 24 (3):7-21. doi: http://dx.doi.org/10.1016/j.tej.2011.02.010.

de Leeuw, Jan, and Erik Meijer. 2008. "Introduction to Multilevel Analysis." In Handbook of Multilevel Analysis, edited by Jan de Leeuw and Erik Meijer, 1-75. New York: SpringerVerlag.

Disney, Richard, Jonathan Haskel, and Ylva Heden. 2003. "Entry, Exit and Establishment Survival in UK Manufacturing." The Journal of Industrial Economics 51 (1):91-112. doi: 10.1111/1467-6451.00193.

Douglas, Stratford M., and Julia N. Popova. 2011. "Econometric Estimation of Spatial Patterns in Electricity Prices." Energy Journal 32 (2):81-105. 
DSIRE. 2012. Incentives/Policies for Renewables \& Efficiency. Database of State Incentives for Renewables and Efficiency (DSIRE).

Dunne, Timothy, Mark J. Roberts, and Larry Samuelson. 1989. "The Growth and Failure of U. S. Manufacturing Plants." The Quarterly Journal of Economics 104 (4):671-698. doi: $10.2307 / 2937862$.

EIA. 2005. "Form EIA-767 historical data files." US Energy Information Administration, Last Modified Nov. 2, 2006 Accessed April 1, 2015. http://www.eia.gov/electricity/data/eia767/.

EIA. 2011. "Form FERC-423." US Energy Information Administration, Last Modified November 30, 2011 Accessed Jan. 3, 2012. http://www.eia.gov/electricity/data/eia423/.

EIA. 2012a. "Electric power sales, revenue, and energy efficiency Form EIA-861 detailed data files." US Energy Information Administration, Last Modified Oct. 29, 2013 Accessed May 20, 2014. http://www.eia.gov/electricity/data/eia861/.

EIA. 2012b. "Existing Nameplate and Net Summer Capacity by Energy Source, Producer Type and State." US Energy Information Administration, Last Modified Nov. 12, 2013 Accessed May 20, 2014. http://www.eia.gov/electricity/data/state/.

EIA. 2012c. "Net Generation by State by Type of Producer by Energy Source." US Energy Information Administration, Last Modified Nov. 12, 2013 Accessed May 20, 2014. http://www.eia.gov/electricity/data/state/.

EIA. 2012d. "Retail Sales of Electricity by State by Sector by Provider (EIA-861)." US Energy Information Administration, Last Modified Nov. 12, 2013 Accessed May 20, 2014. http://www.eia.gov/electricity/data/state/.

EIA. 2013a. "Form EIA-860 detailed data with previous form data (EIA-860A/860B)." US Energy Information Administration, Last Modified Feb 17, 2015 Accessed April 1, 2015. http://www.eia.gov/electricity/data/eia860/.

EIA. 2013b. "Form EIA-923 detailed data with previous form data (EIA-906/920)." US Energy Information Administration, Last Modified March 25, 2015 Accessed April 1, 2014. http://www.eia.gov/electricity/data/eia923/.

EIA. 2014a. Annual Energy Outlook 2014. US Energy Information Administration.

EIA. 2014b. "Electricity Data Browser." Accessed March 21, 2015. http://www.eia.gov/electricity/data/browser/.

EIA. 2014c. "Monthly Energy Review." US Energy Information Administration Accessed Oct. 5, 2014. http://www.eia.gov/totalenergy/data/monthly/.

Elhorst, J Paul. 2014. Spatial Econometrics: From Cross-Sectional Data to Spatial Panels: Springer.

Ellerman, Denny A. 1996. "The competition between coal and natural gas the importance of sunk costs." Resources Policy 22 (1-2):33-42. doi: http://dx.doi.org/10.1016/S03014207(96)00017-7.

Fabrizio, Kira R., Nancy L. Rose, and Catherine D. Wolfram. 2007. "Do Markets Reduce Costs? Assessing the Impact of Regulatory Restructuring on US Electric Generation Efficiency." The American Economic Review 97 (4):1250-1277. doi: 10.2307/30034091.

Fischer, Carolyn, and Richard G. Newell. 2008. "Environmental and Technology Policies for Climate Mitigation." Journal of Environmental Economics and Management 55 (2):142162.

Fischer, Carolyn, and Louis Preonas. 2010. Combining Policies for Renewable Energy: Is the Whole Less than the Sum of its Parts? In Resources for the Future Discussion Paper. 
Fleischman, Lesley, Rachel Cleetus, Jeff Deyette, Steve Clemmer, and Steve Frenkel. 2013. "Ripe for Retirement: An Economic Analysis of the U.S. Coal Fleet." The Electricity Journal 26 (10):51-63. doi: http://dx.doi.org/10.1016/j.tej.2013.11.005.

Gouchoe, SM, VS Everette, and R Haynes. 2002. Case studies on the effectiveness of state financial incentives for renewable energy: National Renewable Energy Laboratory.

Hiebert, L. Dean. 2002. "The Determinants of the Cost Efficiency of Electric Generating Plants: A Stochastic Frontier Approach." Southern Economic Journal 68 (4):935-946. doi: $10.2307 / 1061501$.

Hittinger, Eric, J. F. Whitacre, and Jay Apt. 2010. "Compensating for wind variability using colocated natural gas generation and energy storage." Energy Systems 1 (4):417-439. doi: 10.1007/s12667-010-0017-2.

Jenkins, Stephen P. 1995. "Easy Estimation Methods for Discrete-Time Duration Models." Oxford Bulletin of Economics \& Statistics 57 (1):129-138.

Langniss, Ole, and Ryan Wiser. 2003. "The renewables portfolio standard in Texas: an early assessment." Energy Policy 31 (6):527-535. doi: Doi: 10.1016/s0301-4215(02)00095-2.

Lauby, M. G., J. A. Moura, and E. M. Rollison. 2011. "Accommodating large amounts of variable generation in North America." Power and Energy Society General Meeting, 2011 IEEE, 24-29 July 2011.

LCV. 2013. "National Environmental Scorecard." League of Conservation Voters Accessed Sept. 10, 2014. http://scorecard.lcv.org/.

Lee, Lung-fei, and Jihai Yu. 2010. "Estimation of spatial autoregressive panel data models with fixed effects." Journal of Econometrics 154 (2):165-185. doi: http://dx.doi.org/10.1016/j.jeconom.2009.08.001.

LeSage, James P., and R. Kelley Pace. 2009. Introduction to Spatial Econometrics. Boca Raton, FL: Chapman \& Hall/CRC.

Lyon, Thomas P., and Haitao Yin. 2010. "Why Do States Adopt Renewable Portfolio Standards? An Empirical Investigation." Energy Journal 31 (3):133-157. doi: http://www.iaee.org/en/publications/journal.aspx.

Macmillan, Steven, Alexander Antonyuk, and Hannah Schwind. 2013. Gas to Coal Competition in the U.S. Power Sector. International Energy Agency.

McCall, B. P. 1994. "Testing the proportional hazards assumption in the presence of unmeasured heterogeneity." Journal of Applied Econometrics 9 (3):321-334. doi: 10.1002/jae.3950090307.

Menz, F. C., and S. Vachon. 2006. "The effectiveness of different policy regimes for promoting wind power: Experiences from the states." Energy Policy 34 (14):1786-1796. doi: 10.1016/j.enpol.2004.12.018.

Michaels, Robert J. 2008. "A National Renewable Portfolio Standard: Politically Correct, Economically Suspect." The Electricity Journal 21 (3):9-28. doi: 10.1016/j.tej.2008.03.003.

Moseidjord, Asbjorn. 2004. "California's Soft Renewable Portfolio Standard." Energy Studies Review 13 (1):96-111.

NWS. 2014. "Degree Days Statistics." National Weather Service Climate Prediction Center Accessed Nov 22, 2014. http://www.cpc.ncep.noaa.gov/products/analysis_monitoring/cdus/degree_days/. 
Olley, G. Steven, and Ariel Pakes. 1996. "The Dynamics of Productivity in the Telecommunications Equipment Industry." Econometrica 64 (6):1263-1297. doi: $10.2307 / 2171831$.

Palmer, Karen, and Dallas Burtraw. 2005. "Cost-Effectiveness of Renewable Electricity Policies." Energy Economics 27 (6):873-894.

Puga, J. Nicolas. 2010. "The Importance of Combined Cycle Generating Plants in Integrating Large Levels of Wind Power Generation." The Electricity Journal 23 (7):33-44. doi: http://dx.doi.org/10.1016/j.tej.2010.07.002.

Rothwell, Geoffrey S. 2000. "The Risk of Early Retirement of U.S. Nuclear Power Plants under Electricity Deregulation and CO2 Emission Reductions." Energy Journal 21 (3):61-87. doi: http://www.iaee.org/en/publications/journal.aspx.

Shrimali, Gireesh, and Joshua Kniefel. 2011. "Are government policies effective in promoting deployment of renewable electricity resources?" Energy Policy 39 (9):4726-4741. doi: 10.1016/j.enpol.2011.06.055.

Shrimali, Gireesh, Jenner Steffen, Groba Felix, Chan Gabriel, and Indvik Joe. 2012. Have State Renewable Portfolio Standards Really Worked?: Synthesizing Past Policy Assessments. DIW Berlin, German Institute for Economic Research.

Shuai, Lu, Y. V. Makarov, Zhu Yunhua, Lu Ning, N. P. Kumar, and B. B. Chakrabarti. 2010. "Unit commitment considering generation flexibility and environmental constraints." Power and Energy Society General Meeting, 2010 IEEE, 25-29 July 2010.

Smith, DC, RC Grace, and R Wiser. 2000. "Massachusetts renewable portfolio standard: Cost analysis report." La Capra Associates and Sustainable Energy Advantage, LLC under contract to Massachusetts Division of Energy Resources.

Stoft, Steven. 2002. Power system economics: designing markets for electricity. Piscataway, NJ; New York: IEEE Press ; Wiley-Interscience.

Stoft, Steven E. 2008. "The Surprising Value of Wind Farms as Generating Capacity." SSRN eLibrary.

Syverson, Chad. 2004. "Market Structure and Productivity: A Concrete Example." Journal of Political Economy 112 (6):1181-1222. doi: 10.1086/424743.

US Census Bureau. 2012. Median Household Income by State - 3-Year Averages. US Census Bureau.

Wiser, Ryan, Galen Barbose, and Edward Holt. 2011. "Supporting solar power in renewables portfolio standards: Experience from the United States." Energy Policy 39 (7):38943905. doi: 10.1016/j.enpol.2010.11.025.

Wiser, Ryan, Christopher Namovicz, Mark Gielecki, and Robert Smith. 2007. "The Experience with Renewable Portfolio Standards in the United States." The Electricity Journal 20 (4):8-20. doi: DOI: 10.1016/j.tej.2007.03.009.

Wooldridge, Jeffrey M. 2002. Econometric analysis of cross section and panel data: The MIT press.

Yin, Haitao, and Nicholas Powers. 2010. "Do state renewable portfolio standards promote instate renewable generation?" Energy Policy 38 (2):1140-1149. doi: 10.1016/j.enpol.2009.10.067. 